\title{
Escape of TLR5 Recognition by Leptospira spp.: A Rationale for Atypical Endoflagella
}

\section{OPEN ACCESS}

Edited by:

Melissa Jo Caimano,

University of Connecticut Health

Center, United States

Reviewed by:

John J. Bromfield,

University of Florida, United States

Ellie Jordan Putz,

National Animal Disease Center

(USDA ARS), United States

Juan Anguita,

Center for Cooperative Research

in Biosciences, Spain

*Correspondence:

Catherine Werts

cwerts@pasteur.fr

tThese authors share first authorship

$¥$ Present address: Laurence Fiette, IMMR, Paris, France

Specialty section: This article was submitted to Microbial Immunology, a section of the journal

Frontiers in Immunology

Received: 20 May 2020

Accepted: 24 July 2020

Published: 11 August 2020

Citation:

Holzapfel M, Bonhomme D,

Cagliero J, Vernel-Pauillac F, Fanton d'Andon M, Bortolussi S, Fiette $L$, Goarant $C$, Wunder Jr EA,

Picardeau M, Ko Al, Werling D,

Matsui M, Boneca IG and Werts $C$ (2020) Escape of TLR5 Recognition

by Leptospira spp.: A Rationale

for Atypical Endoflagella.

Front. Immunol. 11:2007.

doi: 10.3389/fimmu.2020.02007

\begin{abstract}
Marion Holzapfel1,2,3†, Delphine Bonhomme ${ }^{1,2,3,4+}$, Julie Cagliero ${ }^{5}$, Frédérique Vernel-Pauillac ${ }^{1,2,3}$, Martine Fanton d'Andon ${ }^{1,2,3}$, Sophia Bortolussi ${ }^{1,2,3}$, Laurence Fiette ${ }^{6 \neq}$, Cyrille Goarant ${ }^{7}$, Elsio A. Wunder Jr. ${ }^{8,9}$, Mathieu Picardeau ${ }^{10}$, Albert I. Ko ${ }^{8,9}$, Dirk Werling ${ }^{11}$, Mariko Matsui ${ }^{5}$, Ivo G. Boneca ${ }^{1,2,3}$ and Catherine Werts ${ }^{1,2,3 *}$

${ }^{1}$ Institut Pasteur, Unité Biologie et Génétique de la Paroi Bactérienne, Paris, France, ${ }^{2}$ CNRS, UMR 2001 Microbiologie Intégrative et Moléculaire, Paris, France, ${ }^{3}$ Institut National de la Santé et de la Recherche Médicale, Equipe Avenir, Paris, France, ${ }^{4}$ Sorbonne Paris Cité, Université de Paris, Paris, France, ${ }^{5}$ Institut Pasteur de Nouvelle Calédonie, Immunity and Inflammation Group, Institut Pasteur International Network, Noumea, France, ${ }^{6}$ Unité Histopathologie Humaine et Modèles Animaux, Institut Pasteur, Paris, France, ${ }^{7}$ Leptospirosis Research and Expertise Unit, Institut Pasteur International Network, Institut Pasteur de Nouvelle Calédonie, Noumea, France, ${ }^{8}$ Gonçalo Moniz Institute, Oswaldo Cruz Foundation, Brazilian Ministry of Health, Salvador, Brazil, ${ }^{9}$ Department of Epidemiology of Microbial Diseases, Yale School of Public Health, New Haven, CT, United States, ${ }^{10}$ Unité Biologie des Spirochètes, Institut Pasteur, Paris, France, ${ }^{11}$ Department of Pathobiology and Population Sciences, Royal Veterinary College, Hatfield, United Kingdom
\end{abstract}

Leptospira (L.) interrogans are invasive bacteria responsible for leptospirosis, a worldwide zoonosis. They possess two periplasmic endoflagellae that allow their motility. $L$. interrogans are stealth pathogens that escape the innate immune recognition of the NOD-like receptors NOD1/2, and the human Toll-like receptor (TLR)4, which senses peptidoglycan and lipopolysaccharide (LPS), respectively. TLR5 is another receptor of bacterial cell wall components, recognizing flagellin subunits. To study the contribution of TLR5 in the host defense against leptospires, we infected WT and TLR5 deficient mice with pathogenic $L$. interrogans and tracked the infection by in vivo live imaging of bioluminescent bacteria or by qPCR. We did not identify any protective or inflammatory role of murine TLR5 for controlling pathogenic Leptospira. Likewise, subsequent in vitro experiments showed that infections with different live strains of L. interrogans and L. biflexa did not trigger TLR5 signaling. However, unexpectedly, heat-killed bacteria stimulated human and bovine TLR5, but did not, or barely induced stimulation via murine TLR5. Abolition of TLR5 recognition required extensive boiling time of the bacteria or proteinase $\mathrm{K}$ treatment, showing an unusual high stability of the leptospiral flagellins. Interestingly, after using antimicrobial peptides to destabilize live leptospires, we detected TLR5 activity, suggesting that TLR5 could participate in the fight against leptospires in humans or cattle. Using different Leptospira strains with mutations in the flagellin proteins, we further showed that neither FlaA nor Fcp participated in the recognition by TLR5, suggesting a role for the FlaB. FlaB have structural homology to Salmonella FliC, and possess conserved residues important for TLR5 activation, as shown by in silico analyses. Accordingly, we found that leptospires regulate the expression of FlaB mRNA according to the growth phase in vitro, and that infection with $L$. interrogans in hamsters and in mice downregulated the expression of 
the FlaB, but not the FlaA subunits. Altogether, in contrast to different bacteria that modify their flagellin sequences to escape TLR5 recognition, our study suggests that the peculiar central localization and stability of the FlaB monomers in the periplasmic endoflagellae, associated with the downregulation of FlaB subunits in hosts, constitute an efficient strategy of leptospires to escape the TLR5 recognition and the induced immune response.

Keywords: Leptospira, toll-like receptor, innate immunity, Flagelin genes, TLR5, mouse model

\section{INTRODUCTION}

Leptospires are spirochetal bacteria responsible for leptospirosis, a neglected reemerging zoonosis (1). Among the Leptospira genus, which includes more than 60 species and 300 different serovars, Leptospira (L.) interrogans gathers the most pathogenic strains (2). Rodents and other animals can carry leptospires asymptomatically in the lumen of proximal renal tubules, excrete the bacteria in their urine and contaminate the environment. Vertebrates get infected through skin or mucosa. In most cases, humans show either no symptoms or suffer from a flulike mild disease, but may also show acute severe, potentially fatal, leptospirosis. Antibiotic treatments are efficient only if administered at the onset of symptoms. The high number of leptospiral serovars and strains complicates the diagnosis and impairs vaccine strategies.

Leptospira are motile bacteria able to swim very fast in viscous environments. They possess two endoflagella, one inserted at each pole of the bacteria, which do not protrude outside of the bacteria but are localized and rotate within the periplasmic space. As seen in other spirochetes, the leptospiral genomes exhibit an atypically high number of structural flagellar genes, including four FlaB subunits with homology to FliC, the unique flagellin monomer forming the filament of Salmonella spp. The structure of the leptospiral filament and the roles of the different flagellar proteins and additional specific components of leptospires, such as the Fcp proteins (3-7), have been recently elucidated by highresolution cryo-electron microscopy coupled to model building and crystallography analyses (8). These studies revealed that the leptospiral filament has an atypical flattened helical shape, and that the four FlaB subunits constitute the core of the flagellum, surrounded by two FlaA and two Fcp subunits forming a sheath (8).

The innate defense of the host relies, amongst other mechanisms, on activation of the complement system and on the recognition of microbe-associated molecular patterns (MAMPs) by immune receptors, such as the pattern recognition receptors (PRRs) families of Toll-like Receptor (TLR) and NODlike receptor (NLR). After ligand recognition, TLRs and NLRs induce immune inflammatory responses that trigger cellular recruitment, ultimately leading to the destruction of microbes by phagocytes (9).

FliC, the prototypical bacterial flagellin, forms a hairpin-like structure with 4 connected domains designated D0, D1, D2, and D3, with both $\mathrm{C}$ and $\mathrm{N}$ termini associated in the D0 domain (10). The D2 and D3 domains are highly variable and support the antigenic diversity. FliC is recognized by different PRRs. TLR5 is expressed at the surface of cells and recognizes monomers of flagellin through the D1 domain, whereas in the cytosol FliC is recognized through the D0 domain by the NAIP inflammasome, which associates with the IPAF/NLRC4, a NOD-like receptor $(11,12)$. TLR5 is an essential innate immune receptor expressed in the kidney and, along with TLR4, important to control Enterobacteria (13). Moreover it is one of the very few TLRs able to recognize a protein agonist, conferring potent adjuvant properties, and helping adaptive immune responses (14).

We previously showed that Leptospira infection triggers the NLRP3 inflammasome, using the ASC adaptor. The results using ASCko mice reproduced the results obtained with the NLRP3ko mice and suggest that the contribution of other inflammasome receptors, such as the NAIP/NLRC4 would be minimal (15). We also showed that $L$. interrogans escapes recognition by human TLR4 (16) as well as murine and human NOD1 and NOD2 (17). In this work, we investigated whether leptospiral flagellins are either recognized by or also escape recognition by TLR5. Our results suggest that live pathogenic leptospires largely escape recognition by human and murine TLR5, although their FlaB subunits are able to signal through human TLR5. This suggests that the periplasmic localization of the flagella and the concealing of FlaB in the core of the filament contribute to avoiding the TLR5 recognition pathway.

\section{MATERIALS AND METHODS}

\section{Leptospiral Strains and Culture Conditions}

Pathogenic $L$. interrogans serovar Icterohaemorrhagiae strain Verdun, L. interrogans serovar Copenhageni strain Fiocruz L1-130, L. interrogans serovar Manilae strain L495, and the saprophytic L. biflexa serovar Patoc strain Patoc I have been provided by the collection of the National Reference Center for Leptospirosis of the Institut Pasteur in Paris. The L495 derivative bioluminescent strain MFLum1 (18), the clinical isolate Fiocruz LV2756 and its non-mobile $f c p A$ mutant (5), the L. interrogans Manilae flaA2 mutant, as well as the flaB4 mutant of $L$. biflexa Patoc have all been previously described $(3,19)$. The L. biflexa $f c p A$ and L. interrogans Manilae flaB1 mutants have been generated for this study by random mutagenesis (20).

Bacteria were grown in Ellinghausen-McCullough-JohnsonHarris (EMJH) medium (Bio-Rad) at $30^{\circ} \mathrm{C}$ without agitation and weekly passaged, counted using a Petroff-Hauser chamber 
and seeded at $5 \times 10^{6}$ bacteria per $\mathrm{mL}$ (bact $/ \mathrm{mL}$ ). Bacteria in mid-log exponential phase (around $10^{8} \mathrm{bact} / \mathrm{mL}$ ), and bacteria in stationary phase (around 1 to $5 \times 10^{9} \mathrm{bact} / \mathrm{mL}$ ) were harvested from 3-6-day old cultures and 10-14-day old cultures, respectively. Unless otherwise specified, experiments were performed with 1-week old cultures. The L. biflexa Patoc Patoc I strain was passaged twice a week by a 1/250 dilution and seeded at around $5 \times 10^{6} \mathrm{bact} / \mathrm{mL}$. For experiments conducted in New Caledonia, virulent $L$. interrogans serovar Icterohaemorrhagiae strain Verdun was cultured in EMJH medium at $30^{\circ} \mathrm{C}$ under aerobic conditions as previously described (21). For in vitro flaB gene expression assays, cultures of each Leptospira strain were seeded in triplicate at $5 \times 10^{6}$ (Day 0). On Day 3 (exponential growth phase) and Day 14 (stationary growth phase), $5 \times 10^{8}$ bacteria from each culture were harvested and centrifuged at $3,250 \times g$ for $25 \mathrm{~min}$, EMJH was discarded and bacteria were resuspended in $500 \mu \mathrm{L}$ of RNAlater Buffer (Qiagen) for RNA stabilization, kept at room temperature for $2 \mathrm{~h}$ before conservation at $-20^{\circ} \mathrm{C}$ until RNA extraction.

\section{In vivo Infection Experiments Using Leptospires}

Male and female C57BL/6J mice (7- to 10-week old) were used in this study and were obtained from Janvier Labs (Le Genest, France). TLR5 deficient mice (TLR5KO) in a C57BL/6J background were bred at the Institut Pasteur Paris animal facility and were previously described (18). Outbred OF1 mice (Mus musculus) and golden Syrian hamsters (Mesocricetus auratus), initially obtained from Charles River Laboratories, were bred in the animal facility in Institut Pasteur in New Caledonia.

Infections of C57BL/6J mice with L. interrogans strains were conducted as described (22). Just before infection, bacteria were centrifuged at room temperature for $25 \mathrm{~min}$ at $3,250 \times g$, resuspended in endotoxin-free PBS. Infection in mice were done via the intraperitoneal route (IP) with sublethal doses $\left(10^{7}\right.$ bacteria in $200 \mu \mathrm{L}$ of PBS) of pathogenic L. interrogans. Live imaging (IVIS) using the bioluminescent MFLum1 derivative of Manilae L595 has been described earlier (23) and recently reviewed (24). Animals were bled at the facial vein sinus (around 50-100 $\mu$ l of blood, recovered in tubes coated with $20 \mu$ l of EDTA $100 \mathrm{mM}$ ). A drop of urine was retrieved upon first handling of mice. Animals were killed by cervical dislocation and organs frozen in liquid nitrogen before storage at $-80^{\circ} \mathrm{C}$ or fixed in formaldehyde for histopathology.

Virulence of $L$. interrogans Icterohaemorrhagiae strain Verdun was maintained by cyclic passages in golden Syrian hamsters after intraperitoneal (IP) injection of the $\mathrm{LD}_{100}$ at $2 \times 10^{8}$ leptospires before re-isolation from blood by cardiac puncture at 4.5 days post-infection, after euthanasia with $\mathrm{CO}_{2}$.

For in vivo study of flaA and flaB gene expression, 6-8week old healthy animals ( $n \geq 5$ individuals per condition) were infected and experiments were carried out as previously described (21). Briefly, OF1 mice and hamsters were IP injected with $2 \times 10^{8}$ virulent $L$. interrogans Icterohaemorrhagiae strain Verdun in 500-800 $\mu \mathrm{L}$ of EMJH medium, as recently reviewed (25). After euthanasia with $\mathrm{CO}_{2}$, whole blood was rapidly collected by cardiac puncture at $24 \mathrm{~h}$ p.i. and conserved in PAXgene blood RNA tubes (PreAnalytiX, Qiagen) for $2 \mathrm{~h}$ at room temperature to allow stabilization of total RNA before storage at $-20^{\circ} \mathrm{C}$ until RNA extraction.

\section{Ethics Statement}

Animal manipulations were conducted according to the guidelines of Animal Care following the EU Directive 2010/63 EU. All protocols were reviewed and approved (\#2013-0034, and \#HA-0036) by the Institut Pasteur ethic committee (CETEA \#89) (Paris, France), the competent authority, for compliance with the French and European regulations on Animal Welfare and with Public Health Service recommendations.

\section{Histology and Immunohistochemistry}

Transversal sections of kidneys were collected and fixed in formaldehyde $4 \%$ for at least $48 \mathrm{~h}$ at room temperature, embedded in paraffin, and $5 \mu \mathrm{m}$ thick sections were stained with Hematoxylin-Eosin. Immunohistochemistry was performed on dewaxed sections as described (18). A rabbit polyclonal serum against the LipL21 (kindly provided by David Haake) was used $\left(1 / 1000^{\mathrm{e}}\right)$. A Periodic Acid-Schiff (PAS) staining was also associated to the Lip21 immunolabeling to visualize the membranes and brush borders typical of proximal tubules.

\section{qPCR Quantification of Leptospiral DNA in Blood, Urine and Organs}

The leptospiral load in blood, urine and organs was determined by quantitative real-time PCR (qPCR), as described (22). Total DNA from blood and urine (around $50 \mu \mathrm{L}$ ) was extracted using a Maxwell 16 automat with the Maxwell blood DNA and cell LEV DNA purification kits (Promega), respectively. DNA was extracted with the QIAamp DNA kit (Qiagen) from organs mechanically disrupted for $3 \mathrm{~min}$ at $4^{\circ} \mathrm{C}$ with metal beads using an automat (Labomodern). Primers and probe designed in the IpxA gene of L. interrogans strain Fiocruz L1-130 (4) were used to specifically detect pathogenic Leptospira sp. (22), using the nidogen gene for normalization in kidneys. qPCR reactions were run on a Step one Plus real-time PCR apparatus using the absolute quantification program (Applied Biosystems), with the following conditions for FAM-TAMRA probes: $50^{\circ} \mathrm{C}$ for $2 \mathrm{~min}, 95^{\circ} \mathrm{C}$ for $10 \mathrm{~min}$, followed by 40 cycles with denaturation at $95^{\circ} \mathrm{C}$ for $15 \mathrm{~s}$ and annealing temperature $60^{\circ} \mathrm{C}$ for $1 \mathrm{~min}$.

\section{Reverse and Real-Time Transcription PCR for Cytokine Gene Expression in Kidney}

Total RNA was extracted from kidneys using the RNeasy mini kit (Qiagen) and RT-qPCR were performed as described (18). The sequences of primers and probes for IL10, RANTES, and IFN $\gamma$ have already been described $(10,15)$. Data were analyzed according to the method of relative gene expression using the comparative cycle threshold $(\mathrm{Ct})$ method also referred to as the $2^{(-\Delta \Delta \mathrm{Ct})}$ method. PCR data were reported as the relative increase in mRNA transcripts versus that found in kidneys from naive WT mice, corrected by the respective levels of Hypoxanthine 
phosphoribosyltransferase (HPRT) mRNA used as an internal standard.

\section{Total RNA Extraction and cDNA Synthesis for Leptospiral fla Genes}

Total RNA from blood was extracted using a PAXgene blood RNA system from PreAnalytiX (Qiagen). Total RNA from virulent Leptospira $\left(4 \times 10^{8}\right.$ bacteria) cultured in vitro at 30 and at $37^{\circ} \mathrm{C}$ in EMJH medium was also extracted using a High Pure RNA Isolation kit (Roche Applied Science) following the manufacturer's recommendations. Total RNA samples were treated with DNase (Turbo DNA-Free kit; Ambion, Applied Biosystems) for elimination of residual genomic DNA. Before storage at $-80^{\circ} \mathrm{C}$, purified RNA was quantified by measurement of the optical density at $260 \mathrm{~nm}\left(\mathrm{OD}_{260}\right)$ using a NanoDrop 2000 spectrophotometer (Thermo Fisher Scientific), and the quality of nucleic acids was verified by measurement of the $\mathrm{OD}_{260} / \mathrm{OD}_{280}$ ratio. Then, $1 \mu \mathrm{g}$ of total RNA was reverse transcribed using a Transcriptor First Strand cDNA synthesis kit (Roche Applied Science) and the provided random hexamer primers for the mix preparation, on a GeneAmp PCR system 9700 instrument (Applied Biosystems) with the following program: $10 \mathrm{~min}$ at $25^{\circ} \mathrm{C} ; 30 \mathrm{~min}$ at $55^{\circ} \mathrm{C}$; and $5 \mathrm{~min}$ at $85^{\circ} \mathrm{C}$. The cDNA synthesized was conserved at $-20^{\circ} \mathrm{C}$ until quantitative PCR (qPCR) assays.

\section{Quantitative PCR and FlaA and FlaB Expression Analysis}

After cDNA synthesis, qPCR assays were performed using primers purchased from Eurogentec (Seraing, Belgium; Table 1) and specific for the gene coding for the flaA and flaB subunit genes. Primers were designed using LightCycler Probe Design
Software (version 2.0; Roche Applied Science) or the free online Primer3 software (version 0.4.0) using available sequences retrieved from GenBank (NCBI). Amplifications were carried out on a LightCycler 480 II instrument using LightCycler 480 software (v. 1.5.0) and a LightCycler 480 SYBR green I master kit (Roche Applied Science) according to the provided instructions. The amplification program was as follow: a first hot start $\left(95^{\circ} \mathrm{C}\right.$ for $10 \mathrm{~min}$ ) and 50 cycles of an activation step at $95^{\circ} \mathrm{C}$ for $5 \mathrm{~s}$, an annealing step at $62^{\circ} \mathrm{C}$ for $5 \mathrm{~s}$, and an elongation step at $72^{\circ} \mathrm{C}$ for $8 \mathrm{~s}$. Each sample was run in duplicate. A single acquisition of fluorescence for calculation of the $C t$ was processed during the elongation step. The specificity of amplification was verified by size visualization of the PCR product (Table 1) after electrophoresis on a $1.8 \%$ agarose gel (Sigma-Aldrich) in $1 \%$ TBE (Tris-borate-EDTA) for $30-45 \mathrm{~min}$ at $120 \mathrm{~V}$ and by analysis of the melting curves of the PCR products (melting temperatures, $T_{\mathrm{m}}$, in Table 1). All Ct values were analyzed using the qbase ${ }^{\text {PLUS }}$ software (Biogazelle, Belgium).

For in vivo infections, the level of expression of each target gene was normalized to the levels of lipL21, lipL36, and lipL41 gene, previously validated as reference genes in our conditions (26). The relative normalized expression ratio was then calculated as the ratio of the in vivo to the in vitro expression level of bacteria cultured at $30^{\circ} \mathrm{C}$. For the in vitro bacterial cultures, level of expression of flaB genes was normalized to the level of lipL41 housekeeping gene (Normalized relative quantities).

\section{Generation of Bone Marrow-Derived Macrophages (BMM)}

Bone marrow cells (BMC) were obtained as recently described (22). Briefly, mice were euthanized and femurs dissected, cleaned,

TABLE 1 | Details and sequence of primers used for qPCR assays.

\begin{tabular}{|c|c|c|c|c|}
\hline Gene name & Locus tag ${ }^{a}$ & Sequence $\left(5^{\prime}-3^{\prime}\right)^{b}$ & $T_{\mathrm{m}}\left({ }^{\circ} \mathrm{C}\right)^{\mathrm{c}}$ & Size $(p b)^{d}$ \\
\hline \multirow[t]{2}{*}{ flaA1 } & LIC10788 & (F) AGCAAGCGTATCAAGCGA & 81.1 & 151 \\
\hline & & (R) GCATTCTCTCCTGGATAAGTG & & \\
\hline \multirow[t]{2}{*}{ flaA2 } & LIC10787 & (F) CGTCAGAGGATITGATAGAGTG & 80.3 & 210 \\
\hline & & (R) CCAGGAATTGTAGCGGT & & \\
\hline \multirow[t]{2}{*}{ flaB1 } & LIC11890 & (F) GCTGACGGTTCTCTCCTGAC & 80.1 & 280 \\
\hline & & (R) ACGTTAGCCTGAGCAAGCAT & & \\
\hline \multirow[t]{2}{*}{ flaB2 } & LIC11889 & (F) AGCGAGACAACTTCTTCCGCCATA & 78.4 & 150 \\
\hline & & (R) ATGAAGCAGAGAGCGGATATGGGA & & \\
\hline \multirow[t]{2}{*}{ flaB3 } & LIC11532 & (F) GCAAGCGCAAACGCTATGAT & 79 & 180 \\
\hline & & (R) ATCCCTCACACGGCTTTCTG & & \\
\hline \multirow[t]{2}{*}{ flaB4 } & LIC11531 & (F) ACTCCTTACCGGGGCTाTG & 78.8 & 200 \\
\hline & & (R) TCACAGAGTITGCCTTGCCA & & \\
\hline \multirow[t]{2}{*}{ lipL21 } & LIC10011 & (F) TGGTGAAGCTACTGCATCT & 80.0 & 164 \\
\hline & & (R) CACCTGGAAATITTGCG & & \\
\hline \multirow[t]{2}{*}{ lipL36 } & LIC13060 & (F) GGTTCAAATTGCGCTGTAG & 80.8 & 188 \\
\hline & & (R) GCATAAACGGTIITCCGAG & & \\
\hline \multirow[t]{2}{*}{$\operatorname{lip} L 41^{\mathrm{e}}$} & & (F) ПTACCAGTTGCCATAGAAGCGGC & 77.6 & 150 \\
\hline & & (R) GGAAATCTGATTGGAGCCGAAGCA & & \\
\hline
\end{tabular}

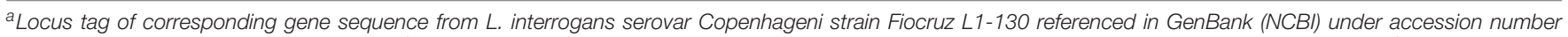

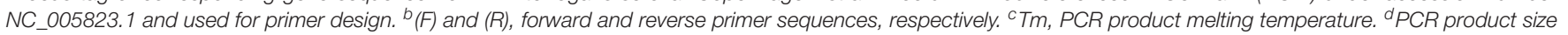
(in base pairs). ${ }^{e}$ As described by Carrillo-Casas et al. (60). 
and the femur heads were cut off. BMC were flushed out using a $21 \mathrm{G}$ needle to inject culture medium through the bones. $\mathrm{BMC}$ were centrifuged $(300 \times g, 5 \mathrm{~min})$ and treated with Red Blood Cell Lysis Buffer (Sigma-Aldrich) for $10 \mathrm{~min}$, followed by PBS washing. BMC were counted, and $5 \times 10^{6}$ cells seeded in $100 \mathrm{~cm}^{2}$ cell culture dishes in $12 \mathrm{~mL}$ RPMI supplemented with $10 \%$ fetal calf serum (Lonza), $1 \mathrm{X}$ non-essential amino acids (NEEA, Gibco), $1 \mathrm{mM}$ sodium pyruvate (complete medium) supplemented with 1X Antibiotic/Anti-mycotic solution (Gibco) and $10 \%$ L929 cell supernatant to provide a source of M-CSF1. Cells were incubated for 7 -day at $37^{\circ} \mathrm{C}$ with $5 \% \mathrm{CO}_{2}$. At day 3 , $5 \mathrm{~mL}$ of the same medium was added. At day 7, the medium was removed, and $3 \mathrm{~mL}$ of cell dissociation buffer (Gibco) was added to harvest the bone marrow macrophages (BMMs). BMMs were collected by scrapping, centrifuged, enumerated and seeded in 96-well plates at a density of $2 \times 10^{5}$ cells per well in complete medium without antibiotics. BMMs were rested for 2$4 \mathrm{~h}$ and stimulated for $24 \mathrm{~h}$ with different leptospiral strains, live or heat-killed for $30 \mathrm{~min}$ at $100^{\circ} \mathrm{C}$, at a MOI of $1: 100$, or 1:50 or with $100 \mathrm{ng} / \mathrm{mL}$ of controls [Standard Flagellin from Salmonella typhimurium (FLA) and LPS E. coli ultra-purified (both from InvivoGen)]. The keratinocyte-derived (KC/CXCL1) was measured in cell supernatants $24 \mathrm{~h}$ post-stimulation, by ELISA using Duo-Set kits (R\&D Systems), according to the supplier's instructions.

\section{TLR5/NF- $к B$ Assay in Human Epithelial Cell Line HEK-Blue-KD-TLR5}

Human embryonic kidney (HEK)-Blue-KD-TLR5 cells (Invivogen) are HEK293 cells knocked-down (KD) for TLR5. In these HEK-BLUE cells, the activation of NF- $\mathrm{B}$ drives the expression of the secreated alkaline phosphatase (SEAP) enzyme that induces a color shift from pink to blue of the chromogenic substrate in the HEK-Blue Detection Media (Invivogen). These cells were cultured in complete DMEM medium composed of DMEM GlutaMax (Gibco) with $1 \mathrm{mM}$ sodium pyruvate (Gibco), 1X NEEA (Gibco) and 10\% V/V heat-inactivated fetal calf serum (Hi FCS, Gibco). On day 1, cells were detached by 1 min incubation in cell dissociation buffer (Gibco) followed by gentle flush with medium. Cells were then seeded in $22.1 \mathrm{~cm}^{2}$ cell culture dishes (TPP) at less than $30 \%$ confluence and incubated overnight at $37^{\circ} \mathrm{C}, 5 \% \mathrm{CO}_{2}$. Cell transfections were performed on day 2 , whilst the cells remained under $60 \%$ confluence and with a total amount of $3 \mu \mathrm{g}$ of DNA per dish. For each dish, between $100 \mathrm{ng}$ to $1 \mu \mathrm{g}$ of pUNO1-humanTLR5, pUNO1-murineTLR5 (Invivogen), pcDNA3.1-bovine TLR5 (27) or the corresponding empty vector was used, complemented up to $3 \mu \mathrm{g}$ with pcDNA3.1. The transfection reagent $1 X$ FuGENE HD (Promega) in serum free OptiMEM (Gibco) was incubated during $25 \mathrm{~min}$ with the DNA followed by transfection of the cells according to the manufacturer's instruction. On day 3, transfected HEK-BlueKD-TLR5 cells were stimulated in 96-wells plates. Briefly, $20 \mu \mathrm{L}$ Flagellin from Salmonella typhimurium as a control (Standard FLA-ST (Invivogen) or leptospires resuspended in PBS, at a MOI between 1:50 to 1:200 were added in empty wells. Transfected HEK-Blue-KD-TLR5 cells were then gently flushed in PBS and resuspended in HEK-Blue Detection Media (Invivogen) at $2.8 \times 10^{5}$ cells $/ \mathrm{mL}$. $180 \mu \mathrm{L}$ of cell suspension, corresponding to 50000 cells, were then added on top of the agonists in each well and plates were incubated for $24 \mathrm{~h}$ at $37^{\circ} \mathrm{C}, 5 \% \mathrm{CO}_{2}$. In each well, the activation of NF- $\kappa \mathrm{B}$ through TLR5 was assessed by absorbance measurements at $630 \mathrm{~nm}$. All heat treatments were performed under agitation at $300 \mathrm{rpm}$ and in PBS on the diluted leptospires preparations right before addition in the wells. Proteinase K treatments of leptospires (from Tritirachium album, Qiagen) were performed under agitation at $300 \mathrm{rpm}$ in PBS for $2 \mathrm{~h}$ at $37^{\circ} \mathrm{C}$, to avoid killing the leptospires. Such treatment was followed by heat inactivation of the enzyme and bacteria at $100^{\circ} \mathrm{C}$ for $30 \mathrm{~min}$. The non-inactivated fraction and mock treatment without leptospires were also tested on HEK-Blue-KD-TLR5 cells. Leptospires in PBS were also treated with antimicrobial peptides: LL-37 (InvivoGen) and Bmap28 (Protegenix) at different concentrations $(0-250 \mu \mathrm{g} / \mathrm{mL})$ for $2 \mathrm{~h}$.

\section{Alamar Blue Viability Assay for Leptospires}

Survival of leptospires upon treatments with antimicrobial peptides was assessed by Alamar Blue viability assay (28). After $2 \mathrm{~h}$ incubation with LL-37 or Bmap28 in PBS, $2.5 \times 10^{6}$ leptospires in $100 \mu \mathrm{L}$ in 96-well plates were mixed with $80 \mu \mathrm{L}$ of EMJH and $20 \mu \mathrm{L}$ of $10 \times$ Alamar Blue dye. Plates were incubated in a humid container at $30^{\circ} \mathrm{C}$ for $72 \mathrm{~h}$. Viability of leptospires was visible by the color shift from blue to pink upon resazurin reduction to resorufin by live bacteria. Heat-killed (30 min, $100^{\circ} \mathrm{C}$ ) leptospires were used as control for loss of viability.

\section{In silico Analyses of the Flagellin Protein Sequences}

All the in silico analyses were performed using either Uniprot or GeneBank available sequences. All corresponding accession numbers are mentioned in the figure legends. Amino acid sequence homology percentage (identity) was obtained using BLAST. Alignments of the sequences were performed with MEGA X (29) and using the Clustal method. Structural predictions based on amino acid sequences were obtained using the Phyre2 (30) and figures colored and modified with Chimera (31).

\section{Statistical Analyses}

Statistical analyses were performed using the Student $t$-test, with asterisks corresponding to the following $p$ values: ${ }^{*} p<0.05$; ${ }^{* *} p<0.01 ;{ }^{* * *} p<0.001$.

\section{RESULTS}

\section{TLR5 Deficiency Does Not Modify the Course of Acute Leptospirosis in Mice}

To study the potential involvement of the TLR5 receptor in the host defense against leptospires, we used a murine model of leptospirosis and compared the susceptibility of C57BL6/J (WT) 


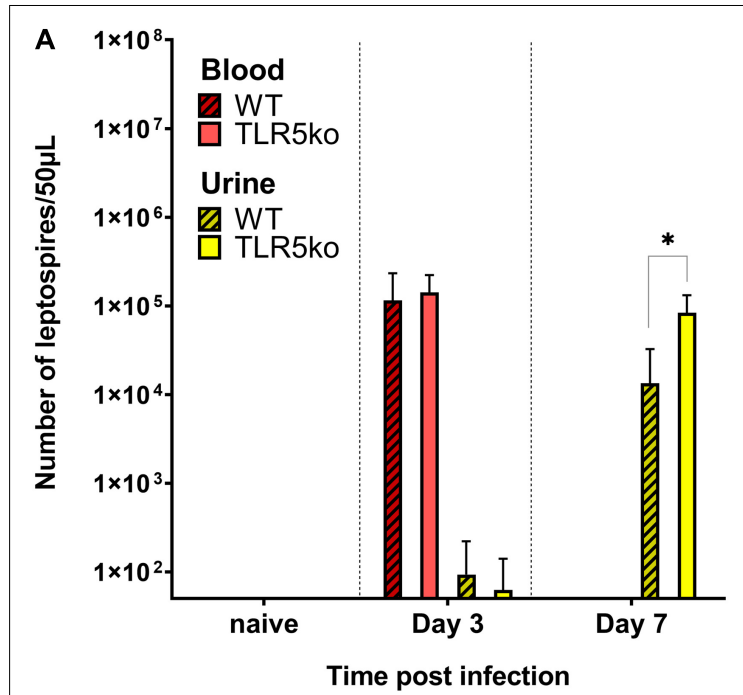

C

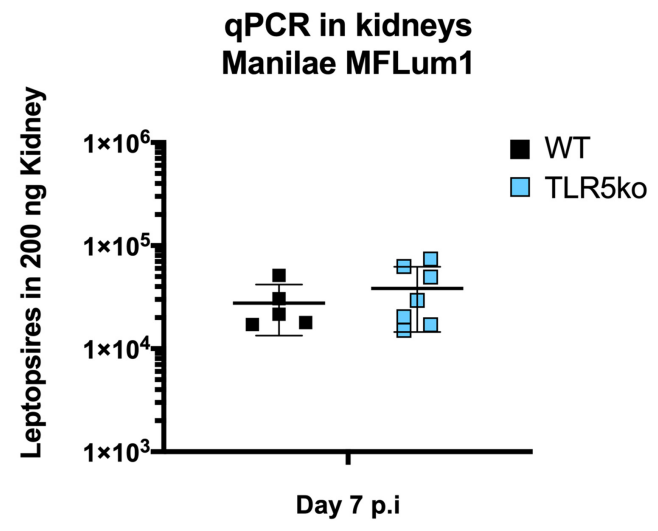

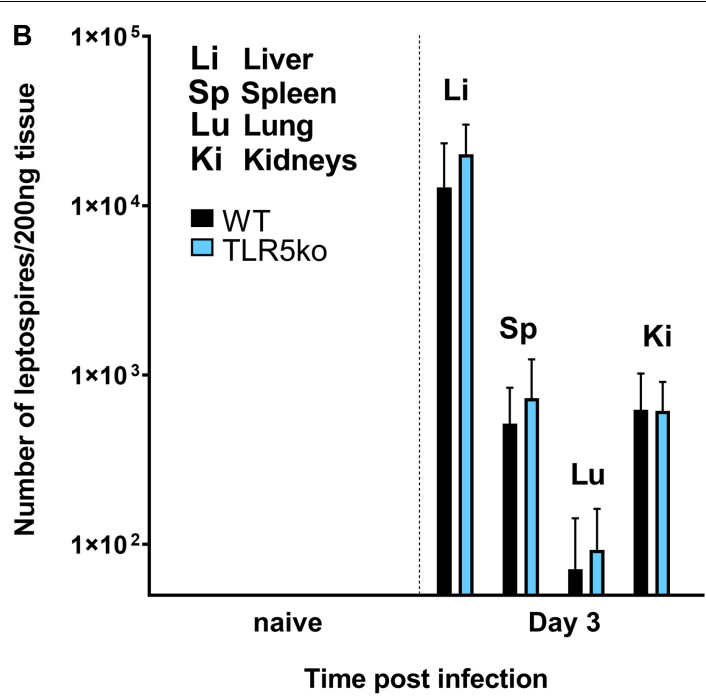

D Cytokines mRNA levels
in kidneys 7 days p.i

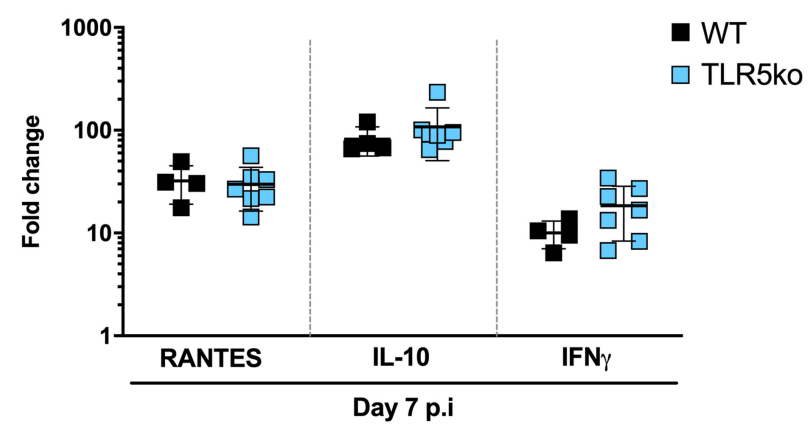

FIGURE 1 | No difference in leptospiral loads and inflammatory mediators between WT and TLR5ko mice during acute phase of leptospirosis. (A,B) Bacterial loads determined by qPCR of leptospiral DNA at several days post intraperitoneal infection of 7-week old female C57BL/6J (WT) mice and TLR5ko mice with $10^{7}$ L. interrogans Manilae L495 derivative strain MFLum1; (A) in blood (red) and urine (yellow) in WT ( $n=4$, hatched bars) and TLR5ko mice ( $n=4$, empty bars) and (B) in liver (Li), spleen (Sp), lungs (Lu) and kidneys (Ki) from WT ( $n=4$, black bars) and TLR5ko ( $n=4$, blue bars) at day 3 post-infection (p.i). Data are expressed as mean $( \pm \mathrm{SD}$ ) of all mice. Statistically significant differences between genotypes (Student $t$-test) are indicated. (C) Bacterial loads in kidneys determined by qPCR 7 days p.i of WT mice ( $n=5$, black dots) and TLR5ko mice ( $n=7$, blue dots). (D) Inflammation measured in kidney by mRNA expression of cytokines (RANTES, IL10, IFN $\gamma$ ) measured by RT-qPCR at 7 days p.i in WT mice ( $n=5$, black dots) and TLR5ko mice ( $n=7$, blue dots). Individual mice are represented as dots and lines correspond to mean $( \pm \mathrm{SD})$ of all mice. No statistical difference was found between WT and TLR5ko mice. ${ }^{*} p<0.05$.

mice versus tlr5 knock-out (TLR5ko) mice after intraperitoneal infection with a sublethal dose of $10^{7} \mathrm{~L}$. interrogans [serovar Manilae strain L495 MFlum1 (23)]. We previously showed in this C57BL6/J mouse model that leptospires disseminate and grow in blood until day 3 and from day 4 post-infection (p.i) progressively disappear from the blood circulation and organs (23). At day 7 p.i, pathogenic leptospires are exclusively found in urine, and in small numbers in kidney, where they progressively grow to establish a stable and lifelong renal colonization from 1-month p.i on. At 15 days p.i, leptospires are easily detected in kidneys either by qPCR or by IVIS imaging $(23,32)$. Here, leptospiral loads were measured by qPCR in blood and urine (Figure 1A) and organs (Figure 1B) in the first week p.i corresponding to the acute phase of infection. As expected, we found leptospires in blood, liver, spleen, lungs and kidney at day 3 p.i (23) (Figures 1A,B), and no difference of leptospiral loads could be observed between WT and TLR5ko mice in blood and organs. At day 7 p.i, leptospires were detected in urines but not in blood (Figure 1A), similar as previously observed (23). However, at day 7 p.i, we measured more leptospires in the urine of TLR5ko mice than in WT mice. Nevertheless, at day 7 p.i, we did not observe any difference in bacterial loads in kidneys between WT and TLR5ko mice (Figure 1C). In addition, mRNA expression of pro-(IFN $\gamma$ ), anti-(IL-10) inflammatory cytokines and RANTES chemokine measured 


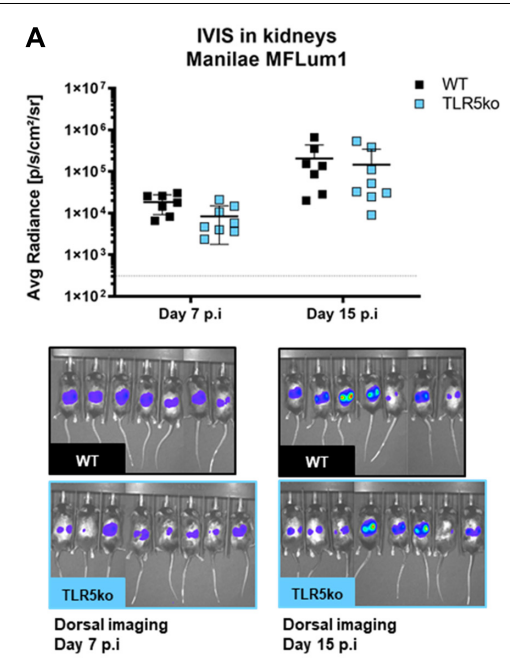

C

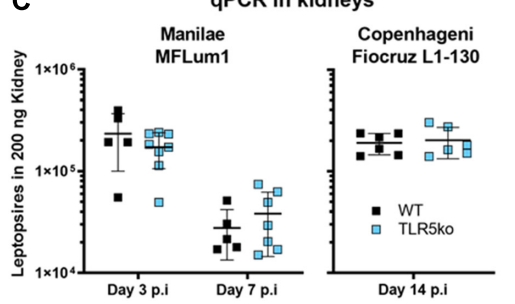

B

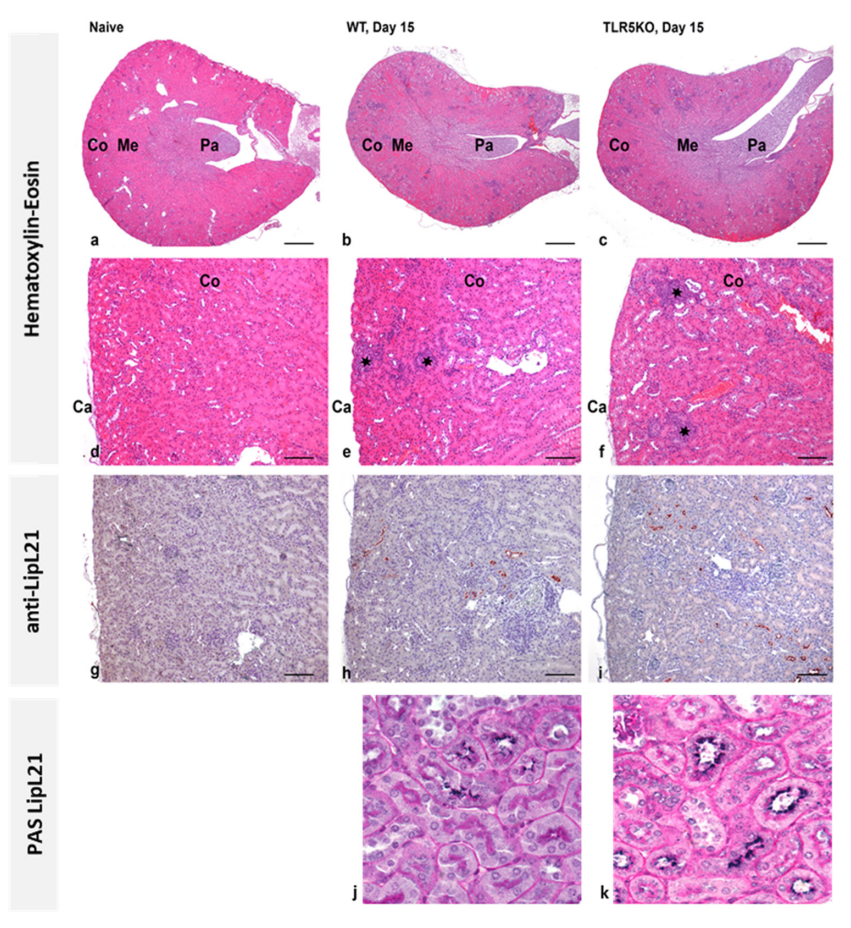

FIGURE 2 | No difference in kidney colonization in WT and TLR5ko mice 15 days post-infection. (A) Bacterial loads in urine quantified by qPCR (left panel), and quantification and images of live imaging (IVIS) (right panel) 15 days post-infection (p.i) of 7-week old female WT mice $(n=7$, black) and TLR5ko mice ( $n=8$, blue) with $10^{7} \mathrm{~L}$. interrogans Manilae bioluminescent derivative strain MFLum1. Imaging was performed in dorsal position, $24 \mathrm{~h}$ post shaving, on anesthetized mice and after luciferin administration. The background level of light after luciferin administration was measured on a control TLR5ko mouse injected with PBS at the time of infection (dotted line). The average radiance in individual mice gated on the whole body is shown and represented as dots; lines correspond to the mean ( \pm SD) of all mice. No statistical difference was found between WT and TLR5ko mice. (B) Bacterial loads in kidneys determined by qPCR of leptospiral DNA 14 days p.i of WT mice ( $n=6$, back dots) and TLR5ko ( $n=6$, blue dots) mice with $10^{7} \mathrm{~L}$. interrogans Copenhageni Fiocruz L1-130. Individual mice are shown and represented as dots; lines correspond to mean $( \pm S D$ ) of all mice. No statistical difference was found between WT and TLR5ko mice. (C) Histological sections and immunolabeling of the kidneys of naive TLR5ko, infected WT and TLR5ko mice 15 days p.i with $10^{7}$ L. interrogans Manilae strain MFLum1. (a-c) Kidney, Hematoxylin-Eosin stain, Original magnification $\times 2$, Scale bar: $500 \mu \mathrm{m}$. Cortex (Co), Medulla (Me), Papilla (Pa), Capsule (Ca). (d-f) Kidney cortex, Hematoxylin-Eosin stain, Original magnification $\times 10$, Scale bar: $100 \mu \mathrm{m}$. The asterisks indicate the focal inflammatory infiltrates. (g-i) Anti-LipL21 labeling of leptospires in renal tubules, Original magnification $\times 10$, Scale bar: $100 \mu \mathrm{m}$. (j,k) Double labeling LipL21/Periodic Acid-Schiff (PAS) to stain the PAS positive brush borders present in proximal tubules only. Original magnification $\times 40$, Scale bar: $25 \mu \mathrm{m}$.

by RT-qPCR at day 7 p.i in the kidneys did not differ between WT and TLR5ko mice (Figure 1D). Altogether these results suggest that the presence of TLR5 does not play a major role in the murine defense at the acute phase of experimental leptospirosis.

\section{TLR5 Deficiency Does Not Impact Renal Colonization}

Next, we established whether the presence of TLR5 is a necessary pre-requisite for the establishment of colonization or the localization of leptospires in the kidneys $(18,32)$. In contrast to day 7 p.i, we found equivalent loads of leptospires in urine from both genotypes 15 days p.i (Figure 2A). Next, we used the bioluminescent property of $L$. interrogans Manilae strain MFLum1 to quantify and visualize leptospires by IVIS imaging in the kidneys of WT versus TLR5ko mice
15 days p.i. The levels and shape of emitted light, reflecting live bacteria (23), were equivalent between WT and TLR5ko infected mice (Figure 2B). In addition, we infected mice with $10^{7}$ L. interrogans Copenhageni Fiocruz strain L1-130, another serovar of pathogenic L. interrogans, and also found by qPCR 15 days p.i equivalent leptospiral loads in kidneys of WT and TLR5ko mice (Figure 2C). Using immunohistochemistry, we further investigated the presence and localization of Manilae L495 leptospires in kidneys of WT and TLR5ko mice, as well as the Leptospira-induced nephritis 15 days p.i (18). Minimal inflammatory cellular infiltrates were noted in the cortex of both WT and TLR5ko infected mice (Figure 2C af), whereas no inflammation was observed in the naive WT control. Labeling of leptospires with an anti-LipL21 antibody (17) revealed Leptospira-infected tubules in the renal cortex, as already described (18) (Figure 2C g-i). In histological sections of the kidney stained with Periodic Acid-Schiff (PAS), we 
found only leptospires in some proximal tubules in both WT and TLR5ko mice associated with the PAS positive microvilli of the brush border at the luminal surface of the tubular epithelium (Figure $\mathbf{2 C} \mathbf{j}, \mathbf{k}$ ), as previously described in rats (33). Altogether, the quantitative assessment by IVIS and qPCR, in combination with the qualitative results obtained by immunohistochemistry suggest that TLR5 does not play a major role in host protection during the acute or chronic phase of a L. interrogans infection in mice.

\section{Live Pathogenic Leptospires Do Not Signal Through Murine and Human TLR5 in vitro}

To further investigate the role of TLR5 in recognition of Leptospira, bone marrow derived macrophages (BMMs) from WT and TLR5ko mice were infected with 3 different live serovars of $L$. interrogans. The production of the murine chemokine KC (CXCL1) was measured by ELISA $24 \mathrm{~h}$ p.i in the cellular supernatants. This chemokine was chosen as it was recently shown to be fully dependent on the MyD88dependent signaling pathway (34), with MyD88 being the first main adaptor involved in TLR5-induced signaling (35). We therefore considered changes in $\mathrm{KC}$ secretion to be a good readout for analyzing TLR5 contribution to the leptospiralinduced signaling. We did not find any difference between both genotypes (Figure 3A), which correlated with the in vivo experiments and indeed strongly supports the observation that live leptospires do not induce signaling through murine TLR5.

Next, we assessed whether the lack of signaling through or escape of recognition by murine TLR5 is a species-specific phenomenon. Indeed, we previously highlighted PRR speciesspecificities of leptospiral MAMPs recognition, such as murine TLR4 receptor that only partially recognizes the leptospiral LPS (34), whereas human TLR4 does not. Conversely, human, but not the murine NOD1 is able to sense leptospiral muropeptides $(17,36)$. We therefore used the human HEK-blue reporter cells, with a NF- $\mathrm{B}$ promoter driving SEAP expression, which can be measured using a colorimetric test. We transfected HEK-BlueKD-TLR5 cells, which are Knocked-Down for TLR5, with either human TLR5, murine TLR5, or an empty control vector. No signal corresponding to murine or human TLR5-mediated NF$\kappa \mathrm{B}$ activation was obtained upon infection with different live L. interrogans serovars at MOI 10 and 100 (data not shown) or even at an MOI of 200 (Figure 3B), which suggested that leptospires also evade human TLR5 recognition or at least do not signal through this TLR.

\section{Heat-Killed Leptospires Signal Through Human TLR5, but Only the Heat-Killed Fiocruz Strain Signals Through Murine TLR5}

The specificity of TLR5 activation and resulting signaling is usually assessed by denaturing a potential ligand through heat-inactivation. In the present study, we observed that inactivation of strains Manilae L495 and Icterohaemorrhagiae Verdun at $100^{\circ} \mathrm{C}$ for $30 \mathrm{~min}$ induced equivalent levels of $\mathrm{KC}$ production in WT and TLR5ko murine BMMs (Figure 3C), which was consistent with the results obtained using live bacteria (Figure 3A). In contrast, the heat-killed Copenhageni Fiocruz strain L1-130 induced less KC secretion in TLR5ko compared to WT BMMs (Figure 3C), suggesting that an agonist present in the inactivated Fiocruz strain could be recognized by murine TLR5. Unexpectedly, heat-killed leptospires from all serovars strongly activated HEK-Blue-KD-TLR5 transfected with human TLR5 (Figure 3D). Further, despite the fact that both strains, Manilae L495 and Icterohaemorrhagiae Verdun, did not stimulate murine TLR5, a slight activation signal was observed with the Copenhageni Fiocruz L130 strain, which was consistent with the chemokine result in BMMs (Figure 3C). The experiment was performed in parallel with an empty plasmid, showing that these results were indeed specific to TLR5 activation, and did not depend on a different NF- $\kappa$ B activation pathway (Figure 3D). Altogether these unexpected results suggested that only heatkilled leptospires can signal through human TLR5, but not or only barely through murine TLR5, providing a new example of species-specificity of PRR recognition of leptospiral MAMPs.

\section{A Heat-Resistant Protein From Heat-Killed Leptospires Signals Through TLR5}

To our knowledge, our results showing TLR5 activation using heat-inactivated leptospires have never been described before. Thus, we first ensured that the signal observed was indeed attributed to proteins of leptospires interacting with TLR5. Since only the stimulation with heat-killed bacteria resulted in TLR5 signaling, we anticipated that a proteinase $\mathrm{K}$ treatment would destroy the protein involved in the signaling. Therefore, we treated live and heat-killed Fiocruz L1-130 leptospires with proteinase $\mathrm{K}$, followed or not by heating at $100^{\circ} \mathrm{C}$ for $30 \mathrm{~min}$ to inactivate the enzyme. We stimulated TLR5 transfected HEKBlue-KD-TLR5 with these preparations and a mock control without bacteria. Although the proteinase $\mathrm{K}$ treatment had no effect on live bacteria, it decreased the signal on heat-killed bacteria (Figure 4A). In contrast to live bacteria treated with proteinase $\mathrm{K}$ and subsequently heated, which resulted in a strong TLR5 activation, TLR5 signaling was not restored in heat-killed bacteria treated with proteinase $\mathrm{K}$, suggesting that the proteinase $\mathrm{K}$ had digested all TLR5 agonists (Figure 4A). This experiment confirmed the protein nature of the agonist present in heat-killed leptospires, which was not affected by proteinase $\mathrm{K}$ digestion in live bacteria. We hypothesize that in live leptospires, the periplasmic location of the endoflagella could protect the flagellin subunits from proteinase $\mathrm{K}$ digestion, thus potentially explaining why live bacteria do not signal through TLR5 and are not affected by the enzyme (Figure 4B).

Next, we investigated the unusual thermostability of the TLR5 agonist, by incubating live Fiocruz L1-130 leptospires at different temperatures (from $30^{\circ} \mathrm{C}$ and up to $99^{\circ} \mathrm{C}$ ) and for different durations (from $30 \mathrm{~min}$ and up to $8 \mathrm{~h}$ ) (Figure 4C) before stimulation of HEK-Blue-KD-TLR5 transfected with human TLR5. Interestingly, after $8 \mathrm{~h}$ incubation at $30^{\circ} \mathrm{C}$ (the optimal temperature for leptospiral growth in vitro) or at $37^{\circ} \mathrm{C}$ (the host 


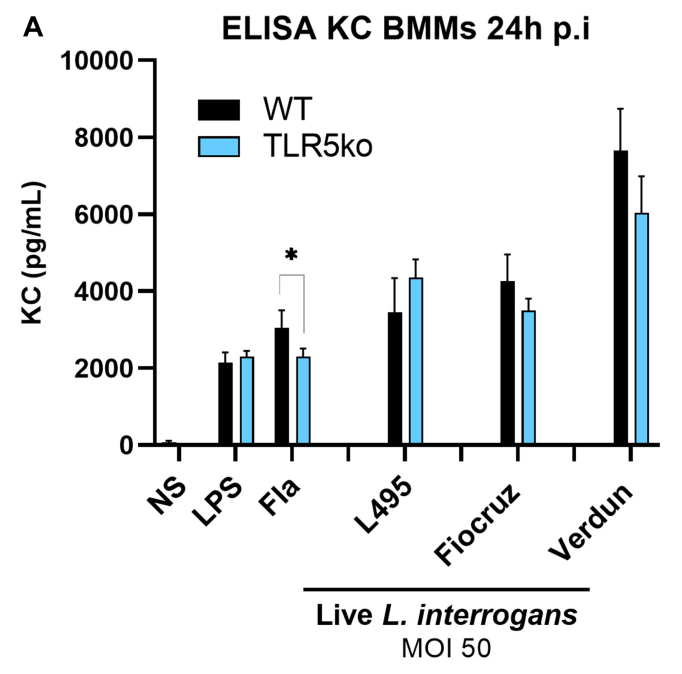

B

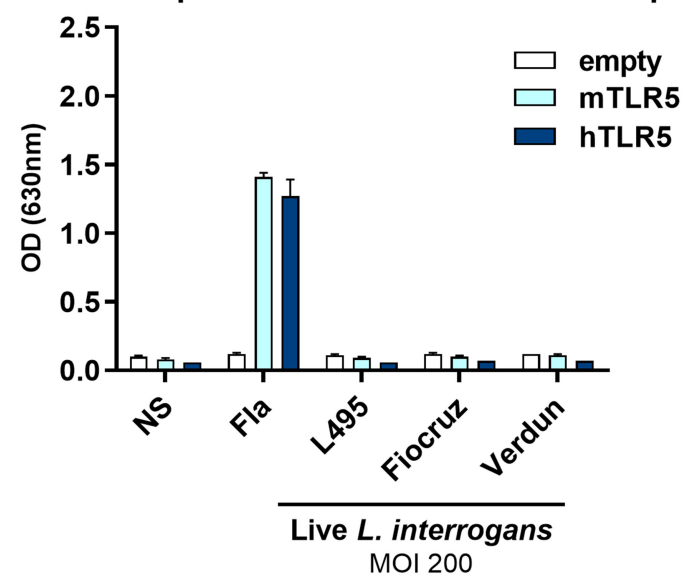

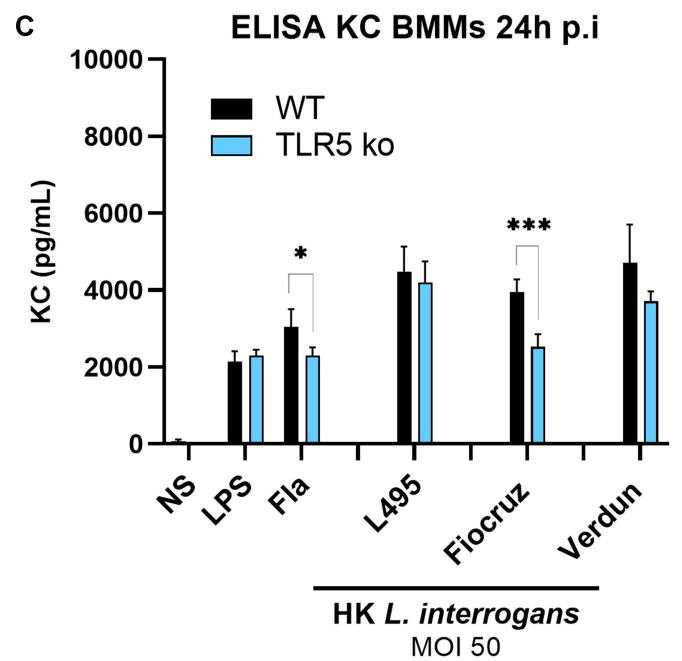

D

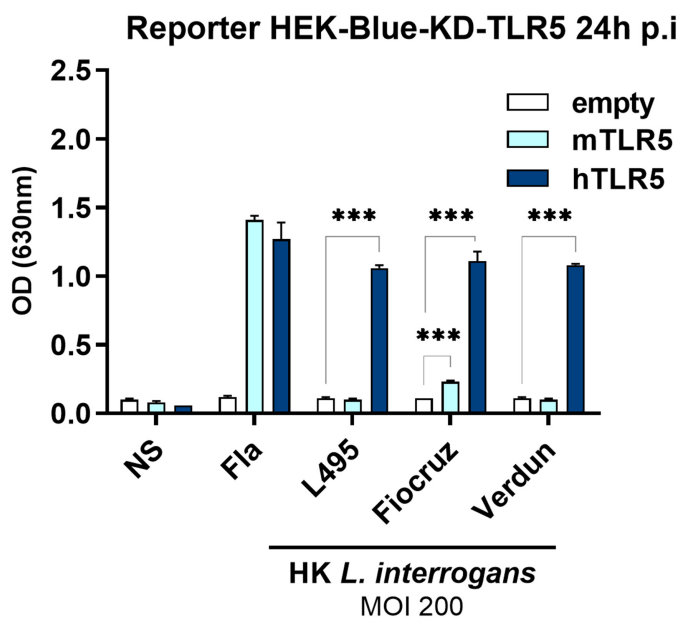

FIGURE 3 | Heat-killed, but not live leptospires, signal through hTLR5. (A,C) KC production measured by ELISA in the supernatants of BMMs from WT (black bars) and TLR5ko (blue bars) mice $24 \mathrm{~h}$ post-infection with $\mathrm{MOI} 50$ of either (A) live or (C) heat-killed (30 min, $\left.100^{\circ} \mathrm{C}\right)$ different serovars of virulent $\mathrm{L}$. interrogans (Manilae strain L495, Copenhageni strain Fiocruz L1-130, Icterohaemorrhagiae strain Verdun). LPS from E. coli (100 ng/mL) and unpurified Fla from Salmonella typhimurium $(500 \mathrm{ng} / \mathrm{mL})$ were used as controls. Data are expressed as mean $( \pm \mathrm{SD})$ of technical replicates $(n=5)$ on pooled BMMs preparations from mice $(n=3)$ and are representative of at least three independent experiments. Statistically significant differences between genotypes (Student $t$-test) are indicated. (B,D) NF-кB reporter assay in HEK-Blue-Knock Down (KD)-TLR5 cells transfected with the mouse TLR5 (light blue bars), human TLR5 (blue bars), or empty plasmid (empty bars) and stimulated for $24 \mathrm{~h}$ with $\mathrm{MOI} 200$ of either (B) live or (D) heat-killed (30 min, 100 $\mathrm{C}$ ) different serovars of virulent $\mathrm{L}$. interrogans. Unpurified Fla from Salmonella typhimurium $(100 \mathrm{ng} / \mathrm{mL})$ was used as control. Data are expressed as the mean $( \pm \mathrm{SD})$ of technical replicates $(n=3)$ and are representative of at least three independent experiments. Statistically significant differences (Student $t$-test) are indicated. ${ }^{\star} p<0.05 ;{ }^{* \star \star} p<0.001$.

temperature), we did not observe any TLR5-dependent signaling. Of note, at $56^{\circ} \mathrm{C}$, the usual temperature to inactivate leptospires $(15,18)$ whilst keeping the leptospiral shape integrity, a signal started after $3 \mathrm{~h}$ of incubation, but even $8 \mathrm{~h}$ were not enough to get a full TLR5 signaling. At $70^{\circ} \mathrm{C}$, the temperature classically used to depolymerize the Salmonella's flagellum filament (10), a $30 \mathrm{~min}$ incubation was sufficient to stably activate TLR5 for $8 \mathrm{~h}$. The signal observed with leptospires incubated for $30 \mathrm{~min}$ at $85^{\circ} \mathrm{C}$ disappeared after $8 \mathrm{~h}$, whereas the positive signal observed after heating the bacteria at $99^{\circ} \mathrm{C}$ for $30 \mathrm{~min}$ disappeared after $3 \mathrm{~h}$ of heating (Figure 4C). We then tested in parallel the Manilae L495 and Copenhageni Fiocruz L1-130 strains, after heating at
30,70 , and $99^{\circ} \mathrm{C}$ for $3 \mathrm{~h}$, and obtained similar results for both 2 serovars (Figure 4D). These results confirmed the protein nature of the TLR5 agonist of leptospires, since the activation can be extinguished by heating the bacteria for an extended time at high temperature.

\section{Antimicrobial Peptides Destabilize Live Leptospires and Unmask a TLR5 Signal}

Since we revealed the potential for TLR5 recognition of leptospires by heating at high non-physiological temperatures, we wondered whether leptospires could signal through 


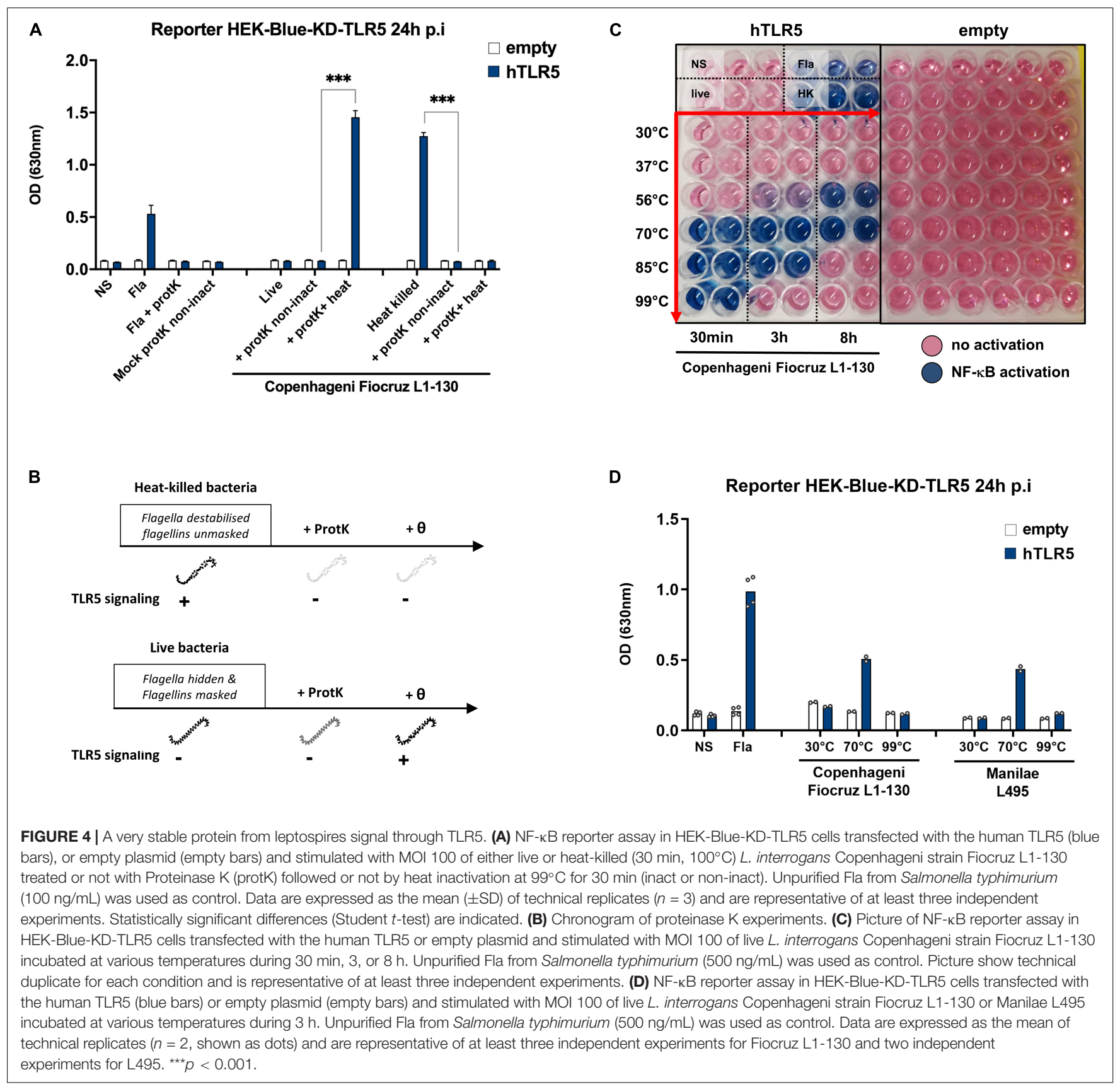

TLR5 after being destabilized or killed with antibiotics or antimicrobial peptides. Antibiotic treatments of the leptospires (at MIC concentrations) including gentamicin, azithromycin, daptomycin and penicillin $\mathrm{G}$, the latter being known to target the cell wall, didn't induce any TLR5 signal (Supplementary Figure 1A). Next, we tested the effect of two different antimicrobial peptides (AMP), LL37 and Bmap28. Cathelicidin LL-37 is an AMP which has been shown to be active against leptospires (37), and its presence was recently associated with a better outcome in human patients with leptospirosis (38). Furthermore, LL-37 has also been shown to prevent death in young hamsters experimentally infected with the Fiocruz L1-130 strain (38). The second AMP, bovine Bmap28 has been described to be 50-100 times more efficient in killing leptospires compared to LL-37, but this depended on the serotypes (37). Therefore, we first tested the ability of both AMP to kill strains Manilae L495 and Copenhageni Fiocruz L1-130. Using an Alamar blue viability assay, we observed that both strains were killed after $2 \mathrm{~h}$ of incubation with $25 \mu \mathrm{g} / \mathrm{mL}$ of either LL-37 or Bmap28 (Figure 5A). Next, we assessed whether leptospires treated with the different doses of AMP were recognized by human TLR5. Interestingly, both, live L. interrogans Manilae L495 and Copenhageni Fiocruz L1-130 bacteria pre-treated with either 25 or $250 \mu \mathrm{g} / \mathrm{mL}$ of LL-37 or Bmap28 induced a significant 
A Alamar Blue viability assay of leptospires incubated with antimicrobial peptides
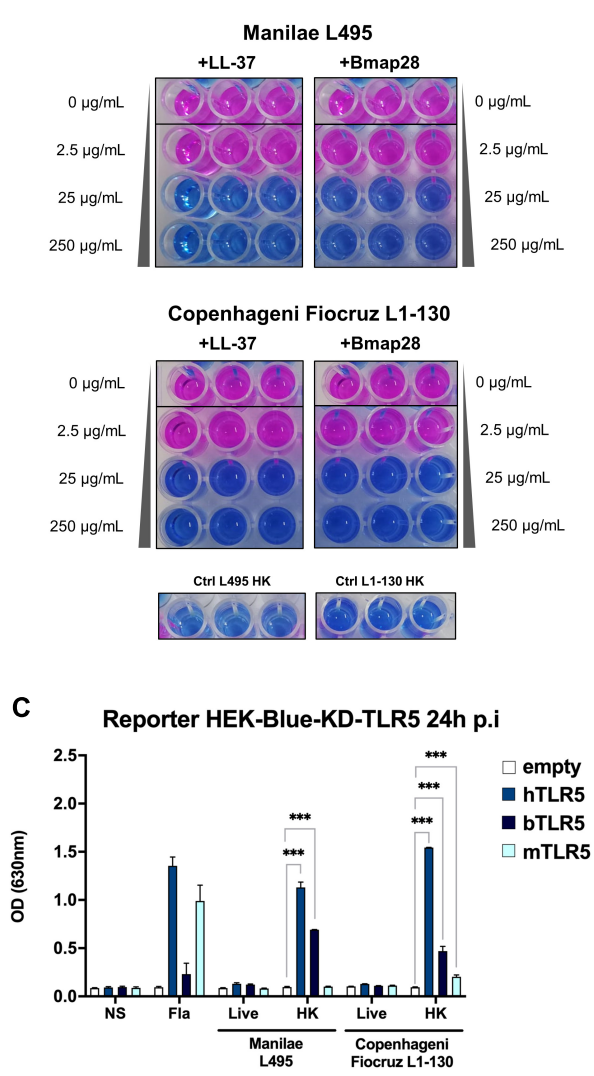

B
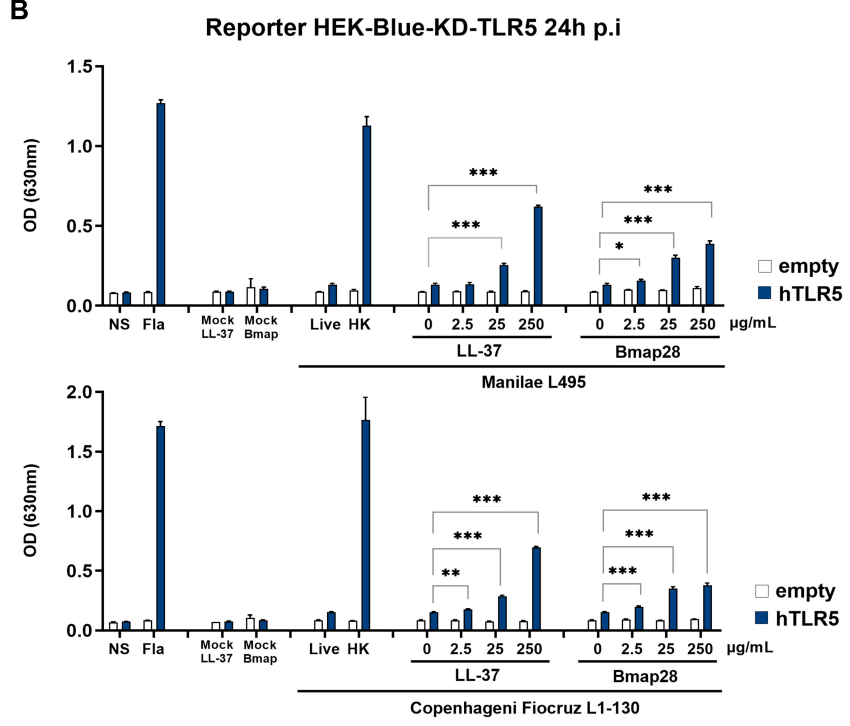

D

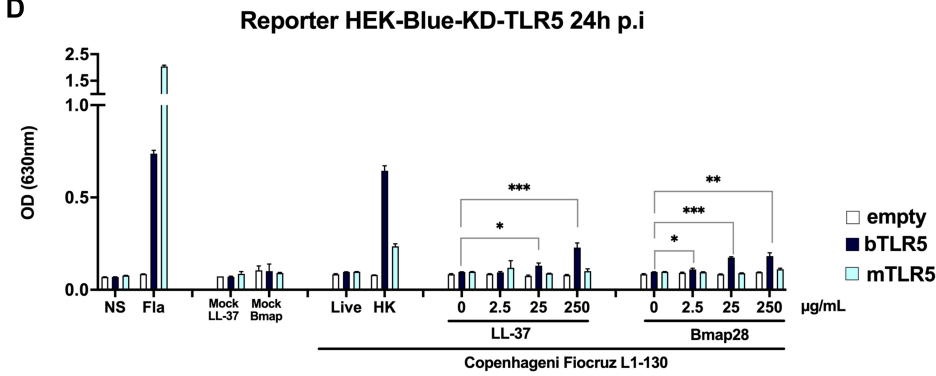

FIGURE 5 | Human and bovine antimicrobial peptides unmask the leptospiral ability to signal through human and bovine TLR5 receptors. (A) Alamar blue viability assay of leptospires (Manilae L495 or Copenhageni Fiocruz L1-130) incubated with increasing concentration (0-250 $\mu \mathrm{g} / \mathrm{mL})$ of antimicrobial peptides LL-37 or Bmap28 for $2 \mathrm{~h}$. Heat-killed $\left(30 \mathrm{~min}, 100^{\circ} \mathrm{C}\right)$ leptospires are used as controls for loss of viability. Picture show technical triplicate for each condition and is representative of two independent experiments. (B) NF-KB reporter assay in HEK-Blue-KD-TLR5 cells transfected with the human TLR5 (blue bars), or empty plasmid (empty bars) and stimulated with MOI 100 of L. interrogans Manilae strain L495 or Copenhageni strain Fiocruz L1-130 treated with human peptide LL-37 or bovine peptide Bmap28 at various concentration (0-250 $\mu \mathrm{g} / \mathrm{mL}$ ) for $2 \mathrm{~h}$ before stimulation. (C) NF-KB reporter assay in HEK-Blue-KD-TLR5 cells transfected with the human TLR5 (blue bars), bovine TLR5 (dark blue bars), mouse TLR5 (light blue bars) or empty plasmid (empty bars) and stimulated with MOI 100 of either live or heat-killed $\left(30 \mathrm{~min}, 100^{\circ} \mathrm{C}\right)$ L. interrogans Manilae strain L495 or Copenhageni strain Fiocruz L1-130. (D) NF-kB reporter assay in HEK-Blue-KD-TLR5 cells transfected with the bovine TLR5 (dark blue bars), mouse TLR5 (light blue bars) or empty plasmid (empty bars) and stimulated with MOI 100 of $L$. interrogans Copenhageni Fiocruz L1-130 treated with human peptide LL-37 or bovine peptide Bmap28 at various concentration (0-250 $\mu \mathrm{g} / \mathrm{mL})$ for $2 \mathrm{~h} \mathrm{before} \mathrm{stimulation.} \mathrm{(B-D)}$ Unpurified Fla from Salmonella typhimurium $(500 \mathrm{ng} / \mathrm{mL})$ was used as control. Data are expressed as the mean $( \pm$ SD) of technical replicates $(n=3)$, and are representative of at least three independent experiments for panels (A) and (C). Statistically significant differences (Student $t$-test) are indicated. ${ }^{*} p<0.05$; ${ }^{* \star} p<0.01 ;{ }^{* \star *} p<0.001$.

and dose-dependent signal in human TLR5 (Figure 5B). These results suggest that antimicrobial peptides could participate in vivo in the exposure of flagellins and subsequently recognition by and signaling through TLR5.

As one of the AMP used was of bovine origin (bovine Bmap28) and pre-treatment of leptospires with Bmap28 had a clear effect on human TLR5 signaling, we tested whether bovine TLR5 could indeed recognize leptospires. In accordance with published data (27), bovine TLR5 reacted only weakly to the positive control, Salmonella derived FliC (Figure 5C). In contrast, we found that it recognized heat-killed Manilae L495 and Copenhageni Fiocruz L1-130 (Figure 5C). Interestingly, the treatment of live Fiocruz L1-130 (Figure 5D) and live L495 (Supplementary Figure 1B) with both AMP (LL37 and Bmap28) resulted in a dose-dependent bovine TLR5 signaling response. However, both treatments, even at high concentration, did not result in a significantly increased signaling response when leptospires were incubated on cells expressing murine TLR5 (Figure 5D and Supplementary Figure 1B). These data suggest that, in vivo, degraded leptospires could be recognized by and signal through human and bovine TLR5, and confirm that mouse TLR5 does not recognize leptospires (Figure 5D).

\section{In silico Analyses of Potential TLR5 Binding of Leptospiral FlaBs}

Two leptospiral flaA (flaA1 and flaA2) genes and four flaB genes (flaB1 to flaB4) have been annotated in the L. interrogans 
A

\begin{tabular}{|c|cc|}
\multicolumn{1}{c}{} & \multicolumn{2}{c}{ L. interrogans } \\
\cline { 2 - 3 } \multicolumn{1}{c|}{} & FlaBs & FlaAs \\
\hline FliC & $38 \%$ & $25 \%$ \\
\hline
\end{tabular}

Salmonella typhimurium FliC
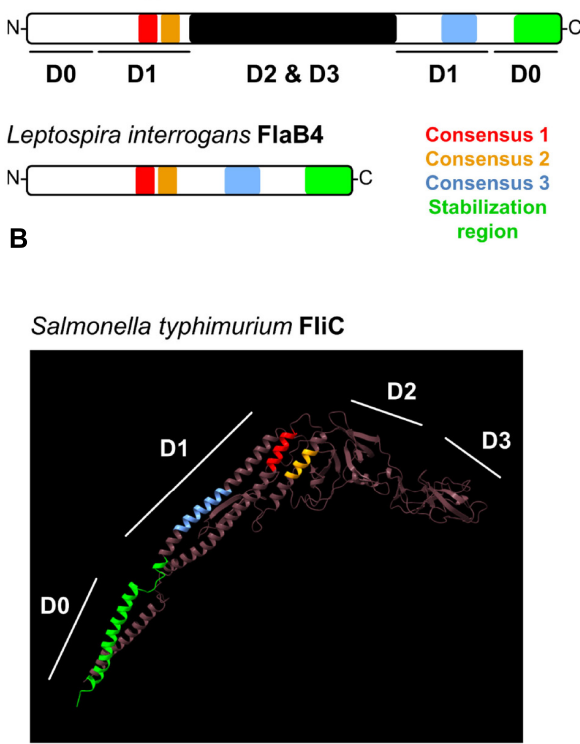

C

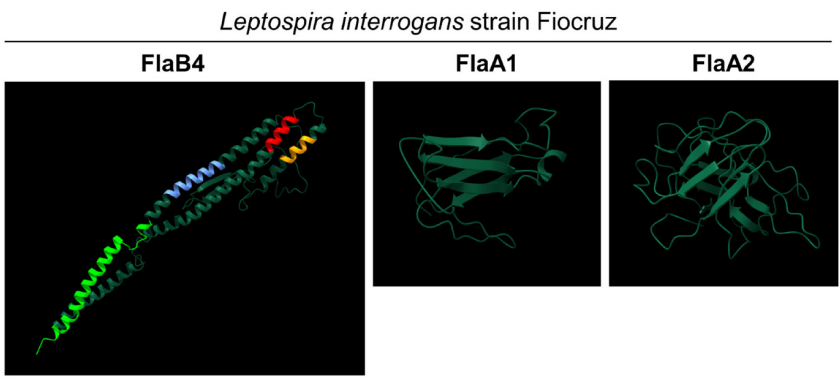

D

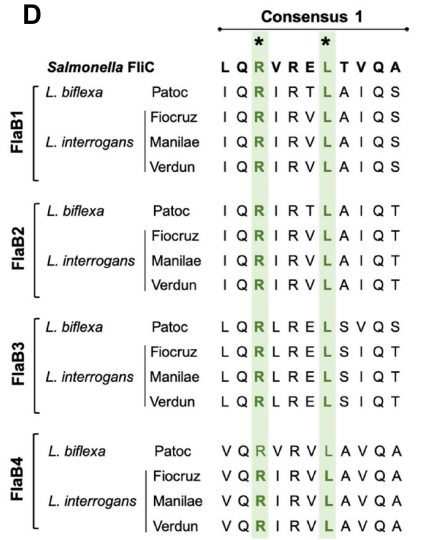

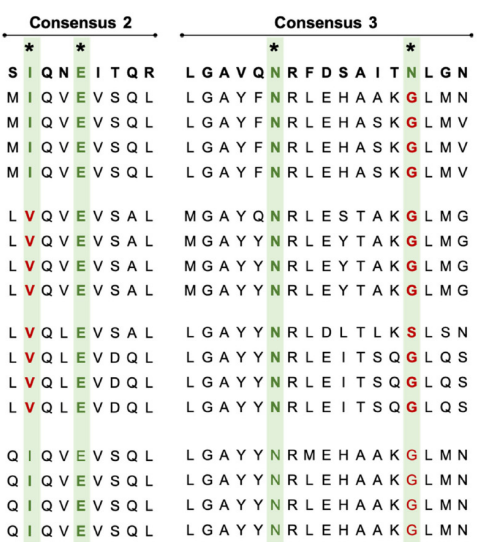

FIGURE 6 | Comparison of leptospiral Flagellins and FliC structures in relation with TLR5. (A) Amino acid sequence homology average percentage between Salmonella typhimurium FliC (P06179) and Leptospira interrogans strain Fiocruz FlaB (LIC11890, LIC11889, LIC11532 and LIC11531) and FlaAs (LIC10788 and LIC10787) and primary structures of the flagellin proteins with TLR5 binding consensus. (B) In silico (Phyre2 and Chimera softwares) prediction of Salmonella typhimurium FliC (P06179) structure with the four described domains and with positions of the TLR5 binding consensus: 1 (red), 2 (yellow) and 3 (light blue) and stabilization region (light green) highlighted. (C) In silico (Phyre2 and Chimera softwares) prediction of Leptospira interrogans strain Fiocruz FlaB4 (LICl1531) with the positions of the TLRS binding consensus and stabilization region highlighted, FlaA1 (LIC10788), FlaA2 (LICI0787). (D) Clustal (MEGA software) alignment of the amino acid sequences for the TLR5 binding consensus regions of: Salmonella enterica FliC (GeneBank QDQ31983.1), L. bifleva (strain Patoc) FlaB1 (LEPBla2133), FlaB2 (LEPBla2132), FlaB3 (LEPBla1872) and FlaB4 (LEPBla1589), L. interrogans (strain Fiocruz L1-130) FlaB1 (LIC18890), FlaB2 (LICIT889), FlaB3 (LICl1532) and FlaB4 (LIC11531), L. interrogans (strain L495) FlaB1 (LMANv2 260016), FlaB2 (LMANv2 260015). FlaB3 (LMANv2 590024) and FlaB4 (LMANv2 590023), and L. interrogans (strain Verdun) FlaB1 (AKWP_v1_110429), FlaB2 (AKWP_v1_110428) and FlaB3 (AKWP_v1_110068) and FlaB4 (AKWP_v1_110067).

genomes according to their similarity with the Salmonella flagellin (FliC), the two families sharing respectively around 25 and $38 \%$ identity at the protein level with FliC (Figure 6A). Structural studies recently showed that the FlaB subunits constitute the core of the flagellum, and the other subunits constitute an asymmetric outer sheath, with FlaB interacting with FlaA on the concave site and with FcpA on the other side of the curvature. FcpA and FcpB associate in a lattice forming the convex part of the endoflagellum (8) (Supplementary Figure 2A). Using the BLAST-P software, we found that the different FlaB subunits from the L. interrogans Fiocruz strain share $57-72 \%$ of identity and most probably result from gene duplication events (Supplementary Figure 3A). Similar results were obtained with the saprophytic L. biflexa Patoc strain (Supplementary Figure 3A). We then used the Phyre2 software to model the FlaBs structures according to their primary amino acid sequences, using the $\mathrm{FliC}$ protein sequence as a base. FliC folds in four regions D0 to D3, forming an inverted $\mathrm{L}$ shape (Figure 6B), with both $\mathrm{N}$-term and C-term in the D0 domain.
Region D1, in the inner face of the monomer, is involved in the interaction of FliC with the leucine-rich repeat (LRR) domains of TLR5 via 3 binding sites (Figures 6A,B and Supplementary Figure 2B) (39, 40). There is also a region in the C-term part of the D0 domain that is not directly involved in the binding to TLR5 but important for the stabilization of the TLR5 dimers upon binding to FliC (Figures 6A,B and Supplementary Figure 2B) (41). Phyre 2 predictions showed that all FlaB subunits from L. interrogans and L. biflexa harbor orthologs of the D0 and D1 domains of FliC, while missing the D2 and D3 domains (Figure 6C, and data not shown). We also checked whether FlaA1 or FlaA2 could have a structure mimicking the D2-D3 domains of FliC, but leptospiral FlaA1 and FlaA2 looked globular, mainly presenting $B$ sheets and do not resemble the missing domains (Figure 6C). Interestingly, we found that the FlaB possessed the 3 conserved sequences important for TLR5 binding in the D1 domain (Figures 6A-D). Then, we compared the different pathogenic L. interrogans and the saprophytic L. biflexa Patoc I strain and found that the four FlaB, although 
distinct from each other (Supplementary Figure 3A), were highly conserved in the consensus regions of the TLR5 binding domains in D1 (99-100\% identity among the different pathogenic serovars, the Patoc FlaB being less conserved) (Figure 6D). We also found in FlaB the consensus in the D0 domain involved in the flagellin/TLR5 complex stabilization (Figures 6A,C). We compared the leptospiral FlaB sequences in these 3 consensus binding TLR 5 regions with other spirochetes, Borrelia burgdorferi and Treponema spp., the latter known to signal via TLR5 when FlaB are expressed as recombinant proteins (42) and also with bacteria known to dodge the TLR5 response such as Helicobacter pylori (43) and Bartonella bacilliformis (10), presenting variations in those consensus sequences of their flagellins (Supplementary Figure 4A). In addition, we also found this $\mathrm{FlaB}$ region to be $100 \%$ conserved in a panel of major species of Leptospira circulating all over the world, including potential human pathogens, such as L. borgpeterseni, L. kirschneri, L. noguchii, L. weilii, L. santarosai, as well as L. licerasiae, belonging to another clade of species of lower virulence (2) (Supplementary Figure 4B). These alignments show that the TLR5 binding site region is highly conserved in all leptospiral FlaBs. Therefore each of the four FlaB subunit could potentially signal through TLR5, since leptospiral FlaBs share the 2 first consensus with TLR 5 activating bacteria and the different residue observed in the consensus number 3 is also present in TLR5activating Treponema flagellins (44).

\section{FlaB, Not FlaA Nor Fcp, Induce TLR5 Signaling}

To confirm the putative role of the FlaB subunits in inducing TLR5 signaling, we used different available mutants deficient in either FlaA, FlaB or Fcp subunits to stimulate HEK-blue reporter cells transfected with human TLR5. Of note, both flaAs and $f$ genes are in operons, and the flaA 2 mutant lacks both FlaA1 and FlaA2 subunits (3). Likewise, the $f c p A$ mutant lacks both FcpA and FcpB subunits $(5,6)$. Our results showed that the TLR5 signaling induced with the heat-killed $f c p A$ mutants in Fiocruz LV2756 was equivalent to the activation observed with parental strains (Figure 7A). Moreover, we confirmed this result by using a $f c p A$ mutant of the saprophytic L. biflexa Patoc Patoc I strain (Figure 7A). Likewise, TLR5 signaling was not changed comparing heat-killed WT Manilae L495 and the flaA2 mutant (Figure 7B). However, the heat-killed flaB1 mutant induced a lower activation than its parental counterpart (Figure 7C). We also observed a decrease of the TLR5 response with the Patoc I flaB4 mutant (Figure 7C). These results suggest that the FlaB subunits, but not the FlaA or Fcp, are involved in the TLR5 signaling, and are in line with sequence comparison data.

\section{FlaB mRNA Are Upregulated in Stationary Phase}

Proteomic and high throughput mass spectrometry performed with the Fiocruz L1-130 strain grown in EMJH have shown that all four flaBs genes were expressed and part of the leptospiral flagellum (7). To test whether leptospires could differently regulate the FlaBs expression, cultures of leptospires were harvested after 3-6 days, or after 10-14 days of culture corresponding to exponential growth or stationary phase, respectively. mRNA was purified and RT-qPCR performed with specific primers of the four leptospiral $f l a B$ genes. The results suggested that the mRNA expression of the different FlaB subunits might vary during bacterial growth in vitro (Figure 8A). Indeed, the gene expressions of all FlaB subunits of the Copenhageni Fiocruz L1-130 strain were upregulated at the stationary phase compared to the exponential phase (Figure 8A). In contrast, in the Icterohaemorrhagiae Verdun strain, only the expression of FlaB3 was upregulated at the stationary phase, whereas both, FlaB2 and FlaB3 were upregulated at the stationary phase in the Manilae L495 strain (Figure 8A). Since in prokaryotes the process from transcription to translation is very rapid, these results of flaB mRNA expression together with TLR5 sensing suggest an unanticipated upregulation of the FlaB subunits at the stationary phase or conversely a downregulation at the exponential phase that could potentially influence the TLR5 sensing.

\section{In vivo Infection of Rodent Models Leads to Downregulation of flaB mRNA}

To further investigate whether FlaB regulation could be relevant or play a role in vivo, mice and hamsters were infected with the virulent Icterohaemorrhagiae Verdun strain, as described previously (21). Blood was sampled to purify total mRNAs $24 \mathrm{~h}$ p.i, when leptospires start their exponential growth in blood of mice (23). In parallel, in vitro cultures were performed in EMJH either at $37^{\circ} \mathrm{C}$, the host temperature or at $30^{\circ} \mathrm{C}$, the usual leptospiral growth culture conditions. First, the expressions of flaA1 and flaA2 were not different at $30^{\circ} \mathrm{C}$ and $37^{\circ} \mathrm{C}$ (Supplementary Figure 5), nor between the in vitro conditions and in vivo conditions, either in mice or hamsters (Figure $\mathbf{8 B}$ ). However, the FlaB expressions were strikingly different, with a weaker expression of the FlaB subunits in the hosts compared to the in vitro cultures at $30^{\circ} \mathrm{C}$ (Figure 8C) or $37^{\circ} \mathrm{C}$ (Supplementary Figure 5). These data strongly suggest that $24 \mathrm{~h}$ p.i, compared to in vitro cultures, leptospires downregulate the expression of their FlaBs subunits in animal blood, which as a consequence could participate in the TLR5 avoidance.

\section{DISCUSSION}

In the present study, we showed that live leptospires largely evade induction of signaling through TLR5 and even may escape recognition by TLR5. However, TLR5 agonists were unexpectedly released after boiling for $30 \mathrm{~min}$, and we further showed that these have an unusual thermoresistance. We determined that the TLR5 activity relied, as expected, on the FlaB subunits, known to form the core of the flagella. This subunit also shares some structural features and consensus domains of TLR5 binding with the FliC flagellin subunit of Salmonella. Our results also highlight the species specificity of the TLR5 recognition of the leptospiral FlaBs, and potentially differences among serovars. Indeed, we evidenced that human and bovine TLR5 recognized heat-killed leptospires, although the mouse TLR5 


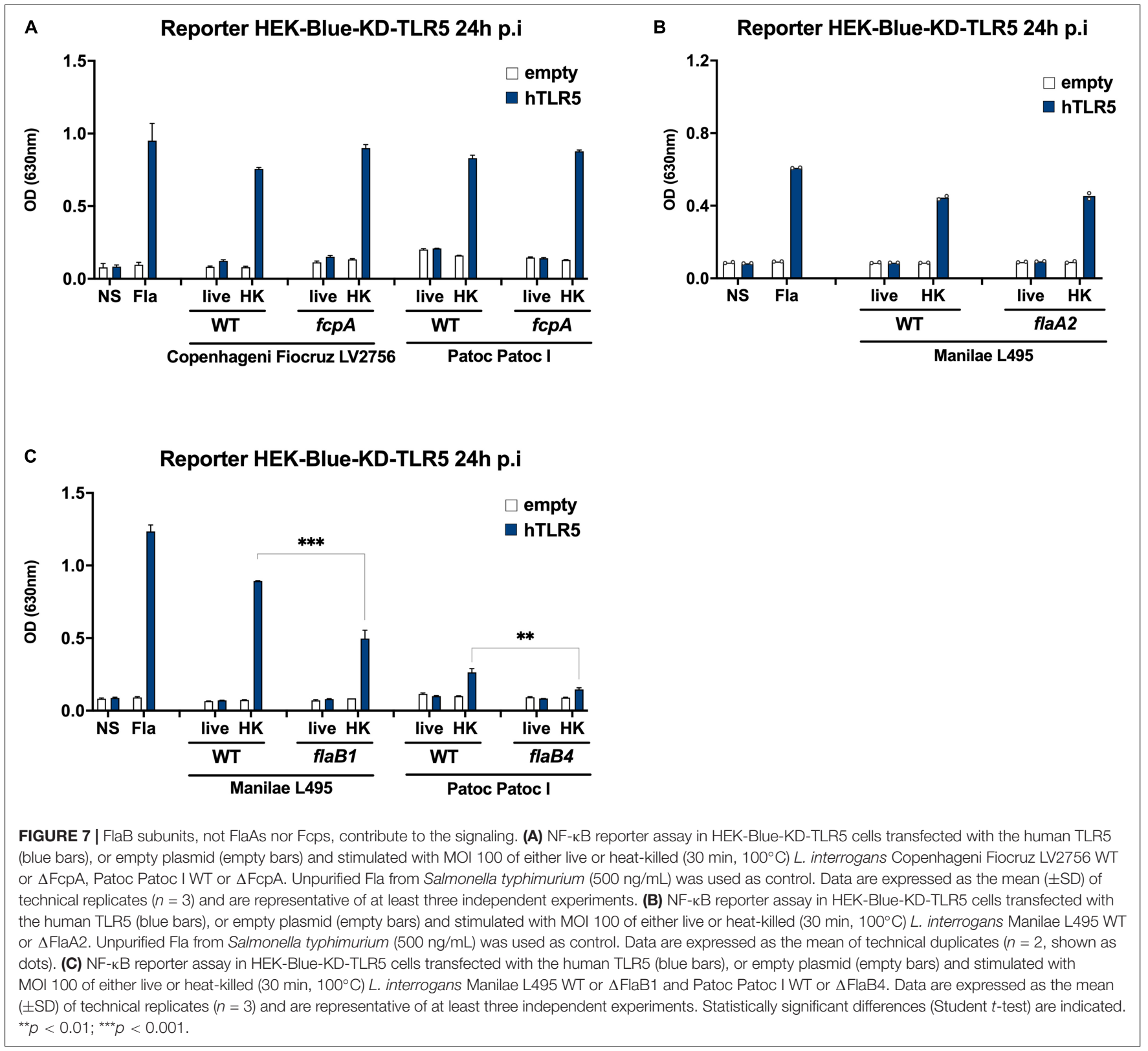

did not sense the Icterohaemorrhagiae Verdun and Manilae L495 strains, but recognized the Copenhageni Fiocruz L1-130 strain, although scantily. We showed that antimicrobial peptides were active against live bacteria and allowed for their signaling through human and bovine TLR5, but not through mouse TLR5. Finally, we showed that leptospires downregulated the FlaBs gene expression in blood from both resistant mice and susceptible hamsters, suggesting a mechanism of immune evasion.

Our results of the in vivo analyses performed in blood and in organs suggest that TLR5 does not play a central role in the control of leptospires, neither during the acute nor during the chronic phase of infection in a murine model. Whereas, we found a higher number of leptospires in the urine of TLR5ko mice 7 days p.i, we did not find such differences in either urine or kidneys of mice infected with the two different strains, Manilae L495 and Copenhageni Fiocruz L1-130 at 15 days p.i. This paradox is difficult to explain. Although the number of leptospires was normalized by the volume of urine, one parameter that we did not control was the flux of emitted urine that could have biased our result. Further studies with more animals would be required to check that the urine metabolism is not altered in TLR5ko, leading to an apparent higher excretion compared to WT mice.

The absence of TLR5 response in the mouse model was surprising because (i) it was shown that neutralizing TLR5 antibodies decreased the cytokine response of whole human blood upon infection with L. interrogans (45), (ii) we showed here that antimicrobial peptides could degrade live leptospires and induce human and bovine TLR5 recognition, and (iii) we 

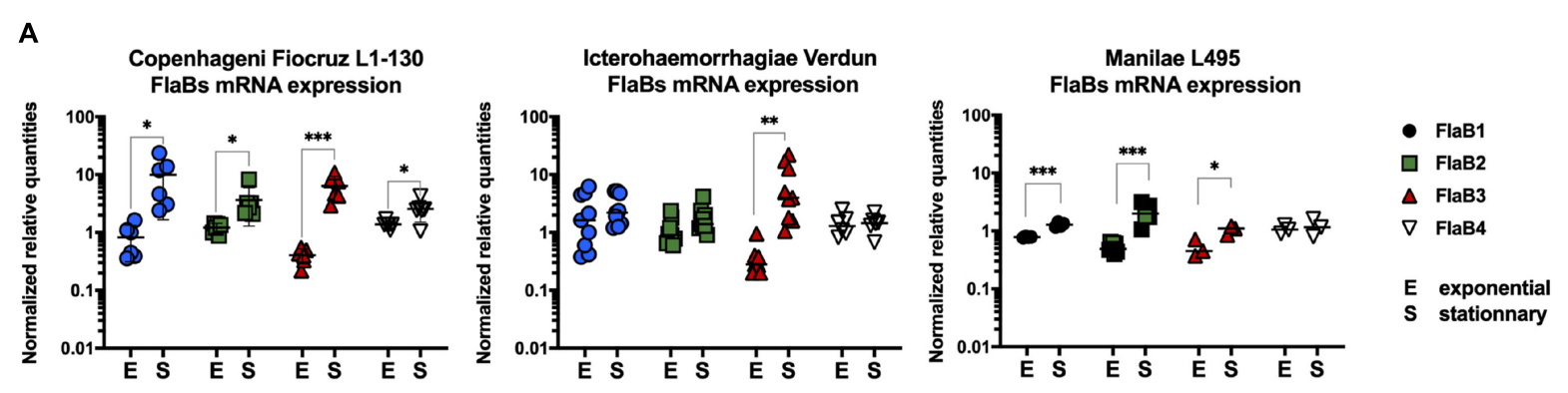

B

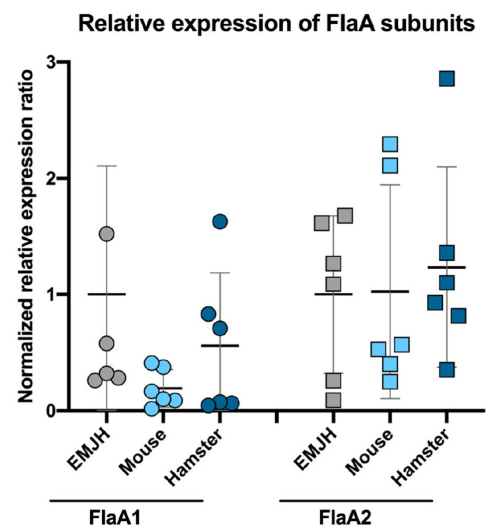

C

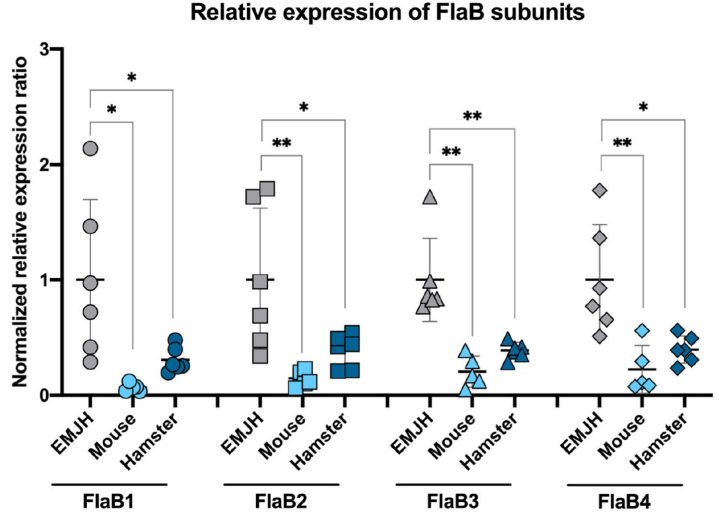

FIGURE 8 | FlaBs mRNA are upregulated in stationary phase and downregulated in vivo. (A) In vitro FlaBs mRNA expression in L. interrogans Copenhageni Fiocruz L1-130, Icterohaemorrhagiae Verdun and Manilae L495 at the exponential (E) and stationary (S) phase. Data of RT-qPCR are expressed as the relative mRNA quantities normalized to the expression of the lip/41 mRNA. Technical replicates are represented as dots and lines correspond to mean ( \pm SD) of replicates

$(3<n<9)$. Statistically significant differences (Student $t$-test) are indicated. (B) In vivo FlaAs and (C) FlaBs mRNA expression in blood of infected mice $(n=5$, light blue) and hamsters ( $n-5$, dark blue), $24 \mathrm{~h}$ post intraperitoneal infection with $2 \times 10^{8}$ virulent $L$. interrogans Icterohaemorrhagiae strain Verdun, compared with mRNA expression in culture in $\mathrm{EMJH}$ at $30^{\circ} \mathrm{C}$. Data of RT-gPCR are expressed as the ratio of mRNA quantities relatives to the EMJH control. Individual animals are represented as dots and lines correspond to mean $( \pm \mathrm{SD})$ of all animals. Statistically significant differences (Student $t$-test) are indicated with corresponding $p$ values: ${ }^{*}$ for $p<0.05 ;{ }^{* \star}$ for $p<0.01$ and ${ }^{* *}$ for $p<0.001$.

previously demonstrated that leptospires were killed and cleared from blood during the first days following infection in mice (23), suggesting the release of free flagellin subunits that could have stimulated the TLR5 response. Hence, our study highlights a species-specificity of the TLR5 recognition since murine TLR5, unlike human and bovine TLR5, was unable to detect the Manilae L495 and Icterohaemorrhagiae Verdun strains. This was unexpected since mouse TLR5 is usually more flexible and able to accommodate more different agonist structures compared to human TLR5 (46), similar to what is seen for human and mouse TLR4 (36). However, the heat-killed Copenhageni Fiocruz L1130 strain was recognized by mouse TLR5, although to a lesser extent than compared to human TLR5. The weak response seen in mouse TLR5 activation is consistent with our previous study showing equivalent levels of IL1ß release in BMMs from WT and TLR5ko mice infected with live Fiocruz L1-130 strain, although stimulation with heat-killed leptospires triggered less IL1ß in TLR5ko BMMs (15). Interestingly, we previously showed by microdissection of the mouse kidney that TLR5 is expressed in renal tubules, mostly in the distal tubules and in the collecting duct cells while almost not expressed in the proximal tubules
(13). However, although Copenhageni Fiocruz L1-130 is the only strain recognized by mouse TLR 5 upon destabilization by heating $(18,47)$, we did not find more leptospires in kidneys of TLR5ko mice compared to WT mice. This result is also in agreement with the fact that treatment with antimicrobial peptides on live leptospires did not unmask a mouse TLR5 signal. Therefore, we may hypothesize that the localization of leptospires in proximal tubules, apart from being the first place to be reached by leptospires and potentially providing rich surroundings for nutrients, could also constitute a favorable environment to avoid the innate TLR 5 response in other animals.

Our results also highlighted an important feature of bovine immune response toward leptospires, since we showed that bovine TLR5 recognizes heated and Leptospira treated with antimicrobial peptides.

Since antimicrobial peptides affect live leptospires allowing for TLR5 recognition and signaling, and because bovine antimicrobial peptides are potent to kill leptospires (37), our results suggest that the bovine TLR5 response may be important to fight leptospires in cattle. Interestingly, bovine TLR5 has been described to present bacterial species-specificity of flagellin 
recognition $(27,48)$. In our study, the magnitude of the Leptospira-induced bovine TLR5 signaling was intermediate between the weak response observed with murine TLR5 and the response seen with human TLR5 (Figure 5C). However, rather than reflect real differences between bovine and human TLR5, this lower response may actually result from the heterologous expression system of bovine TLR5 in the human HEK cell system, that has been shown to impact the responsiveness (48). Together, we speculate that these observed differences in TLR5 sensing between animals and also between the three strains of L. interrogans tested, could, at least partly, be responsible for shaping the preferential species-specificity adaptation of Leptospira serovars to their hosts (49).

Our results showing the lack of TLR5 signaling by live bacteria despite the involvement of the FlaB subunits in the TLR 5 recognition could have been anticipated considering the peculiarities of the leptospiral endoflagella. Indeed, the recent published structure of the filament of the leptospiral flagella showed that the FlaBs form the core and are wrapped inside a lattice composed of both FlaAs, FcpA and FcpB subunits (8) therefore hiding the FlaB monomers. The localization of the flagella inside the periplasm adds another additional layer of protection from the host innate immune system. In addition, in Enterobacteriaceae, a unique FliC monomer polymerizes to form 11 protofilaments that together assemble to constitute one flagellum filament. The consensus sites for TLR5 recognition in the flagellin FliC are localized at stacking sites between the flagellin monomers and therefore are not accessible when the filament is formed. Hence, when polymerized, the interaction domain of FliC with TLR5 is masked, therefore whole flagella do not signal through TLR5, which occurs only when FliC is monomeric $(41,50,51)$. Intact purified periplasmic flagella from Treponema denticola were not able to activate TLR5 as well (52). Interestingly, our data suggest that, similar to Enterobacteriaceae (10), the leptospiral flagellum depolymerizes at $70^{\circ} \mathrm{C}$, which would allow for the release of monomers recognized by the human TLR5. However, in contrast with the Salmonella FliC, which is inactivated after $15 \mathrm{~min}$ at $100^{\circ} \mathrm{C}$, leptospiral flagellins in the context of whole flagella appear to be highly resistant to heating.

Interestingly, we also showed a very high stability of the leptospiral filaments and $\mathrm{FlaB}$ proteins that resist heating to $100^{\circ} \mathrm{C}$ for $30 \mathrm{~min}$ and $85^{\circ} \mathrm{C}$ for $3 \mathrm{~h}$. This unusual thermoresistance of the leptospiral flagella is reminiscent of the hydrophobic and very highly glycosylated pili of hyperthermophilic Archaea (53). Glycosylations also occur in bacteria. Although we do not know whether the Treponema FlaBs are particularly stable, it has recently been shown that the FlaBs of Treponema denticola were glycosylated with an unusual novel glycan (54). Mass spectrometry analysis of these glycopeptides revealed FlaBs glycosylation by O-linkage at multiple sites near the D1 domain, in the very conserved region that interacts with TLR5 (encompassing the end of consensus 2) (Supplementary Figure 6A) (54). Interestingly, we found that these atypical glycosylations target sequences in Treponema, notably the two motifs "VEVSQL" and "DRIAS" are almost 100\% conserved in the FlaB1, FlaB2 and FlaB3 of pathogenic and saprophytic Leptospira (Supplementary Figures 6B,C) (54). In addition, this consensus was also $100 \%$ conserved in leptospiral FlaB1 from other major species involved in leptospirosis in animals and humans (Supplementary Figure 6D). Interestingly, the two serine residues were substituted in the L. interrogans FlaB4 and FlaB from Borrelia burgdorferi (Supplementary Figure 6C), which might suggest a lack of glycosylation of the leptospiral FlaB4 subunit and B. burgdorferi FlaB. The authors hypothesized that in Treponema spp. these peculiar glycosylations could impair the TLR5 signaling of Treponema. Our study suggests, if these post-translational modifications exist in leptospires, that they would not impair the TLR5 recognition at least in human and bovine TLR5. Rather we may speculate that they could participate in the thermoresistance of the filament structure.

In other spirochetes, the filament structure differs from the leptospiral one since in Treponema and Borrelia spp. the FcpA subunits are absent, and beside, in Borrelia only one copy of FlaA and FlaB compose the filament $(55,56)$. The stability of the leptospiral filament is most probably due to the particular association and spatial arrangement of the different FlaBs and to their recently described asymmetric interactions with FlaAs or with Fcps (8). Whether the four FlaBs are randomly dispersed along the filament or would have specific structural functions remains to be studied. However, our results were obtained in the context of the whole bacteria. It would have been interesting to test individual leptospiral FlaB subunits to understand whether the high stability results from intrinsic properties of the individual FlaBs. However, our attempts to express recombinant $\mathrm{FlaB}$ monomers have failed. We cannot exclude a caveat in our cloning strategy but this failure was quite surprising considering that $T$. denticola and T. pallidum FlaB were expressed as stable recombinant proteins that were able to signal through TLR5 in THP1 monocytes or in human keratocytes, respectively (42). One hypothesis could be that the FlaBs that encompass a different shape than FliC would need to be stabilized by polymerization into the complex filament structure.

The respective role of the leptospiral FlaB1, FlaB2, FlaB3 and FlaB4 proteins remains unknown. The Phyre 2 models suggest that the four FlaBs structures are identical, which explains why the precise roles of the different FlaBs in the core could not be addressed in a recent structural study (8). The only information available about differences in the four subunits comes from a proteomic study (7) that finds all four FlaB subunits in Fiocruz L1-130 strain cultured in $\mathrm{EMJH}$ at $30^{\circ} \mathrm{C}$, suggesting that all subunits were present in the filaments with different relative abundance of FlaB subunits. Each bacterium contained 12,000 copies of FlaB1, 2,000 copies of FlaB2, 300 copies of FlaB3 and 3,500 copies of FlaB4 (7). We tested the expression of each of the four FlaBs mRNA in EMJH cultures and found that all the subunits were expressed in the Icterohaemorrhagiae Verdun and Copenhageni Fiocruz L1-130 strains. However, the relative mRNA levels of the different FlaB subunits did not match the data obtained in the proteomic study, since for example the relative mRNA quantities of flaB3 seems to be higher than flaB4 at the stationary phase. Of note the flaB3 mRNA expression was upregulated at the stationary phase in the 3 serovars of $L$. interrogans, for which we have no explanation. 
Of note, the flaB1 expression was upregulated at the stationary phase in Fiocruz L1-130, which could potentially explain the striking difference between the Manilae L495 strain that was not recognized by the mouse TLR5 whereas the Copenhageni L1130 strain exhibited a better recognition, despite the fact that all their FlaBs are almost identical and 100\% conserved in the TLR5 consensus binding domains. In addition, the absence of one FlaB subunit in the flaB4 mutant of L. biflexa Patoc I, which has been shown to impair the filament formation (19), also impairs the TLR5 signaling. A decreased TLR5 signaling was also observed with the Manilae flaB1 mutant although the impact of this mutant on filament formation has not yet been studied. However, in both cases the TLR5 signal was not abolished, suggesting that despite the lack of observed motility and filaments, some other FlaB subunits were still expressed and able to signal through TLR5, in agreement with the in silico analyses suggesting that all FlaB subunits can in theory signal through TLR5.

The fact that we found a striking down-regulation of FlaBs, not of FlaAs, in blood of mice and hamsters $24 \mathrm{~h}$ p.i with the Icterohaemorrhagiae Verdun strain, suggests that a regulation of the FlaBs expression could favor an escape from the TLR5 immune surveillance upon infection. However, it remains to be demonstrated that the global down-regulation of FlaBs expression that we observed in vitro at the exponential phase correlates indeed with a decrease in TLR 5 recognition. In animal blood, the downregulation of the FlaB expression could make sense to avoid the TLR5 response. It would have been interesting to check the expression of the FlaBs in Leptospira colonizing the kidney of animals. However, if amenable in the blood of animals, the purification of leptospires mRNA in kidneys is still challenging. The only example of published renal transcriptome dualseq analysis of L. interrogans (Fiocruz L1-130) infection in mice could only detect 29 leptospiral genes (57), among them lipL32, encoding the major lipoprotein and interestingly, one flagellin gene, flaB4 (LIC11531), suggesting that the mRNA levels of FlaB4 were quite high, and potentially higher than the other FlaBs mRNA. As a whole, these results suggest a complex regulation of the leptospiral FlaB subunits that deserves further investigation. Interestingly, it was shown in another spirochete Brachyspira hyodysenteriae that the flagellin genes are transcribed by different transcription factors, with sigma 28 regulating the flaB1 and flaB2 genes, whereas the flaA and flaB3 genes are controlled by sigma 70 . The authors suggest that the relative ratio of the flagellin proteins could play a role in the stiffness of the flagellar filament and consequently that this regulation may play a role in motility (58). The regulation of FlaBs in leptospires that harbor an even more complex flagellar filament is an interesting question that remains to be studied. Our findings of in vivo downregulation of the FlaBs deserve further studies potentially linking it to regulation of Leptospira motility in vivo.

Interestingly, the leptospiral FlaBs share with the flagellin of Bacillus spp., that is also able to signal via TLR5, a similar structure made of the D0 and D1 domains of FliC and lacking the D2 and D3 domains (59). Of note, the D2 and D3 domains of FliC are highly variable and responsible for the strong antigenicity of flagellins in Enterobacteriaceae (10). Flagellin is known to be a potent vaccine adjuvant, however, the antigenicity of the D2 and D3 domains can be a problem when booster immunizations are done. To circumvent this issue, several strategies have been recently proposed. The first consisted in using a FliC devoid of the D2 and D3 domains (14), and the second to use the Bacillus flagellin as an expression platform (59). Likewise, we may speculate in the case of Leptospira spp. that upon in vivo killing and exposure of FlaB subunits, the lack of D2 and D3 domains could be advantageous to limit the antibody response. Hence, the peculiar structure of FlaBs could also participate in the adaptive immune evasion.

In conclusion, we showed here that pathogenic Leptospira largely escape recognition by TLR5. Other bacteria such as Helicobacter pylori have been shown to escape the TLR 5 response through modification of the amino residues in the D0 or D1 regions of flagellin subunits (43), but leptospires seem to differ in avoiding TLR 5 recognition. Indeed, our data demonstrate that the endoflagella play a role in the escape from TLR5 surveillance, which has never been shown before and might hold true for other spirochetes. We also evidenced regulatory mechanisms of $f l a B$ genes expression that may also play a role in this immune evasion and have important consequences since TLR5 ligation has a potent adjuvant role in immunity.

\section{DATA AVAILABILITY STATEMENT}

All datasets presented in this study are included in the article/Supplementary Material.

\section{ETHICS STATEMENT}

The animal study was reviewed and approved by (\#20130034 and \#HA-0036) the Institut Pasteur ethic committee (CETEA \#89) (Paris, France), the competent authority, for compliance with the French and European (EU directive 2010/63) regulations on Animal Welfare and with Public Health Service recommendations.

\section{AUTHOR CONTRIBUTIONS}

CW: conception, project administration, supervision, and writing original draft. $\mathrm{MH}, \mathrm{DB}, \mathrm{JC}, \mathrm{MM}$, and $\mathrm{CW}$ : visualization. $\mathrm{MH}$, $\mathrm{DB}$, JC, FV-P, SB, MF, MM, CG, and CW: investigation and data analysis. MF and FV-P: validation. LF, FV-P, and MM: methodology. DB and SB: sequences alignment. MP, EW, AK, and DW: resources. CG, EW, IB, and CW: funding acquisition. DW and IB: English editing. All authors contributed to the writing, review and editing of the manuscript, and approved the submitted version. 


\section{FUNDING}

This study received funding from the French Government's Investissement d'Avenir program, Laboratoire d'Excellence "Integrative Biology of Emerging Infectious Diseases" (grant $\mathrm{n}^{\circ}$ ANR-10-LABX-62-IBEID) to IB. DB received funding from the Ecole Doctorale Frontières de l'Innovation en Recherche et Education (FIRE), Program Bettencourt. JC was supported by a Calmette and Yersin fellowship from Institut Pasteur International network and EW by a NIH fund (R01AI121207).

\section{ACKNOWLEDGMENTS}

We thank Brigitte David-Watine for critical reading of the manuscript. We are grateful to Marie-Estelle Soupe-Gilbert for her participation in the design of primers used for the quantification of flagellar subunits gene expression.

\section{SUPPLEMENTARY MATERIAL}

The Supplementary Material for this article can be found online at: https://www.frontiersin.org/articles/10.3389/fimmu. 2020.02007/full\#supplementary-material

FIGURE S1 | Not antibiotics but antimicrobial peptides reveal the L495 ability to activate TLR5. (A) NF-kB reporter assay in HEK-Blue-KD-TLR5 cells transfected with the human TLR5 (blue bars), or empty plasmid (empty bars) and stimulated with $\mathrm{MOI} 100$ of $L$. interrogans Manilae strain $L 495$ treated with gentamicin $(50 \mu \mathrm{g} / \mathrm{mL})$, penicillin $\mathrm{G}(10 \mu \mathrm{g} / \mathrm{mL})$, azithromycin $(10 \mu \mathrm{g} / \mathrm{mL})$ or daptomycin $(1 \mu \mathrm{g} / \mathrm{mL})$ for $4 \mathrm{~h}$ before stimulation. Data are expressed as the mean $( \pm S D)$ of technical replicates $(n=3)$. (B) NF-kB reporter assay in HEK-Blue-KD-TLR5 cells transfected with the bovine TLR5 (dark blue bars), mouse TLR5 (light blue bars) or empty plasmid (empty bars) and stimulated with $\mathrm{MOI} 100$ of $L$. interrogans Manilae strain L495 treated with human peptide LL-37 or bovine peptide Bmap28 at various concentration $(0-250 \mu \mathrm{g} / \mathrm{mL})$ for $2 \mathrm{~h}$ before stimulation. Unpurified Fla from Salmonella typhimurium $(500 \mathrm{ng} / \mathrm{mL})$ was used as control. Data are expressed as the mean $( \pm \mathrm{SD})$ of technical replicates $(n=3)$ and are representative of at least three independent experiments. Statistically significant differences (Student $t$-test) are indicated.

\section{REFERENCES}

1. Ko AI, Goarant C, Picardeau M. Leptospira: the dawn of the molecular genetics era for an emerging zoonotic pathogen. Nat Rev Microbiol. (2009) 7:736-47. doi: $10.1038 /$ nrmicro2208

2. Vincent AT, Schiettekatte O, Goarant C, Neela VK, Bernet E, Thibeaux R, et al. Revisiting the taxonomy and evolution of pathogenicity of the genus Leptospira through the prism of genomics. PLoS Negl Trop Dis. (2019) 13:e0007270. doi: 10.1371/journal.pntd.0007270

3. Lambert A, Picardeau M, Haake DA, Sermswan RW, Srikram A, Adler B, et al. FlaA proteins in Leptospira interrogans are essential for motility and virulence but are not required for formation of the flagellum sheath. Infect Immun. (2012) 80:2019-25. doi: 10.1128/IAI.00131-12

4. San Martin F, Mechaly AE, Larrieux N, Wunder EA Jr., Ko AI, Picardeau M, et al. Crystallization of FcpA from Leptospira, a novel flagellar protein that is essential for pathogenesis. Acta Crystallogr F Struct Biol Commun. (2017) 73:123-9. doi: 10.1107/S2053230X17002096

5. Wunder EA Jr., Figueira CP, Benaroudj N, Hu B, Tong BA, Trajtenberg F, et al. A novel flagellar sheath protein, FcpA, determines filament coiling,
FIGURE S2 | Schematics of leptospiral filament and FliC association with TLR5. Schematic representations of $(\mathbf{A})$ the leptospiral flagellin structure adapted from Gibson et al. (8) and (B) the interaction of FliC subunits with TLR5 inducing dimerization of the receptors adapted from Yoon et al. (40).

FIGURE S3 | BLAST analyses between flagellin subunits and species. (A-C) Amino acid sequence homology percentage between (A) Leptospira interrogans strain Fiocruz FlaBs (LIC11531, LIC18890, LIC11889, LIC11532) and FlaAs (LIC10788, LIC10787), (B) Leptospira interrogans strain Fiocruz FlaBs or Leptospira biflexa strain Patoc FlaBs (LEPBla1589, LEPBla2133, LEPBla2132, LEPBla1872), (C) Leptospira interrogans FlaB1 of all serotypes (Fiocruz LIC11531, Manilae LMANv2_590023, Verdun AKWP_v1_110067, Patoc LEPBla1589), FlaB2 of all serotypes (Fiocruz LIC11890, Manilae LMANv2_260016, Verdun AKWP_v1_110429, Patoc LEPBla2133), FlaB3 of all serotypes (Fiocruz LIC11889, Manilae LMANv2_260015, Verdun AKWP_v1_110428, Patoc LEPBla2132) and FlaB4 of all serotypes (Fiocruz LIC11532, Manilae LMANv2_590024, Verdun AKWP_v1_110068, Patoc LEPBla1872).

FIGURE S4 | TLR5 binding and consensus sites in different species. Clustal (MEGA software) alignment of the amino acid sequences for the TLR5 binding consensus regions of: Leptospira interrogans strain Fiocruz FlaB1 (LIC11531), Leptospira biflexa strain Patoc FlaB1 (LEPBla1589), Borrelia burgdorferi (GeneBank CAA45011.1), Treponema ssp. (GeneBank AlW88993.1), Bacillus subtilis strain W23 (GeneBank ADM39502.1), Salmonella enterica subsp. enterica serovar Typhimurium (GeneBank QDQ31983.1), Escherichia coli strain 0157:H7 (KKF82802.1), Helicobacter pylori strain J99 (GeneBank AKE81874.1) and Bartonnela bacilliformis (GeneBank AAA22899.1).

FIGURE S5 | Temperature of culture medium does not alter FlaAs and FlaBs regulation. FlaAs and FlaBs mRNA expression in culture in EMJH at 30 or $37^{\circ} \mathrm{C}$. Data of RT-qPCR are expressed as the ratio of mRNA quantities relatives to the $\mathrm{EMJH} 30^{\circ} \mathrm{C}$ control. Technical replicates are represented as dots and lines correspond to mean $( \pm S D)$ of all replicates.

FIGURE S6 | Glycosylation sites on FlaBs. (A,B) In silico (Phyre2 and Chimera softwares) prediction of (A) Treponema pallidum strain Nichols FlaB1 (P21990) and (B) Leptospira interrogans strain Fiocruz FlaB1 (LIC11531) with TLR5 binding consensus 2 (yellow) and potential glycosylation positions (pink) highlighted. (C) Clustal (MEGA software) alignment of the amino acid sequences for region with potential glycosylations of: Treponema denticola FlaB (GeneBank

WP_010697276.1), Borrelia burgdorferi (GeneBank CAA45011.1), L. biflexa (strain Patoc) FlaB1 (LEPBla1589), FlaB2 (LEPBla2133), FlaB3 (LEPBla2132), FlaB4 (LEPBla1872), L. interrogans (strain Fiocruz) FlaB1 (LIC11531), FlaB2 (LIC18890), FlaB3 (LIC11889), FlaB4 (LIC11532), L. interrogans (strain Manilae) FlaB1 (LMANv2_590023), FlaB2 (LMANv2_260016), FlaB3 (LMANv2_260015), FlaB4 (LMANv2_590024) and L. interrogans (strain Verdun) FlaB1 (AKWP_v1_110067), FlaB2 (AKWP_v1_110429), FlaB3 (AKWP_v1_110428) and FlaB4 (AKWP_v1_110068).

translational motility and virulence for the Leptospira spirochete. Mol Microbiol. (2016) 101:457-70. doi: 10.1111/mmi.13403

6. Wunder EA Jr., Slamti L, Suwondo DN, Gibson KH, Shang Z, Sindelar CV, et al. FcpB is a surface filament protein of the endoflagellum required for the motility of the spirochete Leptospira. Front Cell Infect Microbiol. (2018) 8:130. doi: $10.3389 /$ fcimb. 2018.00130

7. Malmstrom J, Beck M, Schmidt A, Lange V, Deutsch EW, Aebersold R. Proteome-wide cellular protein concentrations of the human pathogen Leptospira interrogans. Nature. (2009) 460:762-5. doi: 10.1038/nature0 8184

8. Gibson KH, Trajtenberg F, Wunder EA, Brady MR, San Martin F, Mechaly A, et al. An asymmetric sheath controls flagellar supercoiling and motility in the Leptospira spirochete. Elife. (2020) 9:e53672. doi: 10.7554/eLife. 53672

9. Werts C. Interaction of leptospira with the innate immune system. Curr Top Microbiol Immunol. (2017) 415:163-87. doi: 10.1007/82_2017_46

10. Rossez Y, Wolfson EB, Holmes A, Gally DL, Holden NJ. Bacterial flagella: twist and stick, or dodge across the kingdoms. PLoS Pathog. (2015) 11:e1004483. doi: 10.1371/journal.ppat.1004483 
11. Vijayan A, Rumbo M, Carnoy C, Sirard JC. Compartmentalized antimicrobial defenses in response to flagellin. Trends Microbiol. (2018) 26:423-35. doi: 10.1016/j.tim.2017.10.008

12. Matusiak M, Van Opdenbosch N, Vande Walle L, Sirard JC, Kanneganti TD, Lamkanfi M. Flagellin-induced NLRC4 phosphorylation primes the inflammasome for activation by NAIP5. Proc Natl Acad Sci USA. (2015) 112:1541-6. doi: 10.1073/pnas.1417945112

13. Bens M, Vimont S, Ben Mkaddem S, Chassin C, Goujon JM, Balloy V, et al. Flagellin/TLR5 signalling activates renal collecting duct cells and facilitates invasion and cellular translocation of uropathogenic Escherichia coli. Cell Microbiol. (2014) 16:1503-17. doi: 10.1111/cmi.12306

14. Biedma ME, Cayet D, Tabareau J, Rossi AH, vicak-Kocjan KI, Moreno G, et al. Recombinant flagellins with deletions in domains D1, D2, and D3: characterization as novel immunoadjuvants. Vaccine. (2019) 37:652-63. doi: 10.1016/j.vaccine.2018.12.009

15. Lacroix-Lamande S, d'Andon MF, Michel E, Ratet G, Philpott DJ, Girardin $\mathrm{SE}$, et al. Downregulation of the $\mathrm{Na} / \mathrm{K}$-ATPase pump by leptospiral glycolipoprotein activates the NLRP3 inflammasome. J Immunol. (2012) 188:2805-14. doi: 10.4049/jimmunol.1101987

16. Werts C, Tapping RI, Mathison JC, Chuang TH, Kravchenko V, Saint Girons I, et al. Leptospiral lipopolysaccharide activates cells through a TLR2-dependent mechanism. Nat Immunol. (2001) 2:346-52. doi: 10.1038/86354

17. Ratet G, Santecchia I, Fanton d'Andon M, Vernel-Pauillac F, Wheeler R, Lenormand P, et al. LipL21 lipoprotein binding to peptidoglycan enables Leptospira interrogans to escape NOD1 and NOD2 recognition. PLoS Pathog. (2017) 13:e1006725. doi: 10.1371/journal.ppat.1006725

18. Fanton d'Andon M, Quellard N, Fernandez B, Ratet G, Lacroix-Lamande $\mathrm{S}$, Vandewalle $\mathrm{A}$, et al. Leptospira interrogans induces fibrosis in the mouse kidney through Inos-dependent, TLR- and NLR-independent signaling pathways. PLoS Negl Trop Dis. (2014) 8:e2664. doi: 10.1371/journal.pntd. 0002664

19. Picardeau M, Brenot A, Saint Girons I. First evidence for gene replacement in Leptospira spp. inactivation of L. biflexa flaB results in non-motile mutants deficient in endoflagella. Mol Microbiol. (2001) 40:189-99. doi: 10.1046/j. 1365-2958.2001.02374.x

20. Bourhy P, Louvel H, Girons I. S, Picardeau M. Random insertional mutagenesis of Leptospira interrogans, the agent of leptospirosis, using a mariner transposon. J Bacteriol. (2005) 187:3255-8. doi: 10.1128/JB.187.9. 3255-3258.2005

21. Matsui M, Rouleau V, Bruyere-Ostells L, Goarant C. Gene expression profiles of immune mediators and histopathological findings in animal models of leptospirosis: comparison between susceptible hamsters and resistant mice. Infect Immun. (2011) 79:4480-92. doi: 10.1128/IAI.05727-11

22. Santecchia I, Vernel-Pauillac F, Rasid O, Quintin J, Gomes-Solecki M, Boneca IG, et al. Innate immune memory through TLR2 and NOD2 contributes to the control of Leptospira interrogans infection. PLoS Pathog. (2019) 15:e1007811. doi: 10.1371/journal.ppat.1007811

23. Ratet G, Veyrier FJ, Fanton d'Andon M, Kammerscheit X, Nicola MA, Picardeau $\mathrm{M}$, et al. Live imaging of bioluminescent Leptospira interrogans in mice reveals renal colonization as a stealth escape from the blood defenses and antibiotics. PLoS Negl Trop Dis. (2014) 8:e3359. doi: 10.1371/journal.pntd. 0003359

24. Vernel-Pauillac F, Werts C. In vivo imaging of bioluminescent leptospires. Methods Mol Biol. (2020) 2134:149-60. doi: 10.1007/978-1-0716-0459-5_14

25. Cagliero J, Huet K, Matsui M. Use of golden syrian hamster as an animal model to study leptospirosis-associated immune responses. Methods Mol Biol. (2020) 2134:243-55. doi: 10.1007/978-1-0716-0459-5_22

26. Matsui M, Soupe ME, Becam J, Goarant C. Differential in vivo gene expression of major Leptospira proteins in resistant or susceptible animal models. Appl Environ Microbiol. (2012) 78:6372-6. doi: 10.1128/AEM.00911-12

27. Metcalfe HJ, La Ragione RM, Smith DG, Werling D. Functional characterisation of bovine TLR5 indicates species-specific recognition of flagellin. Vet Immunol Immunopathol. (2014) 157:197-205. doi: 10.1016/j.vetimm.2013.12.006

28. Mouville C, Benaroudj N. Survival tests for Leptospira spp. Methods Mol Biol. (2020) 2134:215-28. doi: 10.1007/978-1-0716-0459-5_20

29. Kumar S, Stecher G, Li M, Knyaz C, Tamura K. MEGA $\mathrm{X}$ : molecular evolutionary genetics analysis across computing platforms. Mol Biol Evol. (2018) 35:1547-9. doi: 10.1093/molbev/ msy096

30. Kelley LA, Mezulis S, Yates CM, Wass MN, Sternberg MJ. The Phyre2 web portal for protein modeling, prediction and analysis. Nat Protoc. (2015) 10:845-58. doi: 10.1038/nprot.2015.053

31. Goddard TD, Huang CC, Meng EC, Pettersen EF, Couch GS, Morris JH, et al. Meeting modern challenges in visualization and analysis. Protein Sci. (2018) 27:14-25. doi: 10.1002/pro.3235

32. Chassin C, Picardeau M, Goujon JM, Bourhy P, Quellard N, Darche S, et al. TLR4- and TLR2-mediated B cell responses control the clearance of the bacterial pathogen, Leptospira interrogans. J Immunol. (2009) 183:2669-77. doi: 10.4049/jimmunol.0900506

33. Sterling CR, Thiermann AB. Urban rats as chronic carriers of leptospirosis: an ultrastructural investigation. Vet Pathol. (1981) 18:628-37. doi: 10.1177/ 030098588101800508

34. Bonhomme D, Santecchia I, Vernel-Pauillac F, Caroff M, Germon P, Murray CK, et al. Leptospiral LPS escapes mouse TLR4 internalization and TRIF associated antimicrobial responses through $\mathrm{O}$ antigen and associated lipoproteins. PLoS Pathog. (2020). doi: 10.1101/2020.05.18.101857

35. Werts C, Girardin SE, Philpott DJ. TIR, CARD and PYRIN: three domains for an antimicrobial triad. Cell Death Differ. (2006) 13:798-815. doi: 10.1038/sj. cdd. 4401890

36. Nahori MA, Fournie-Amazouz E, Que-Gewirth NS, Balloy V, Chignard M, Raetz CR, et al. Differential TLR recognition of leptospiral lipid A and lipopolysaccharide in murine and human cells. J Immunol. (2005) 175:602231. doi: $10.4049 /$ jimmunol.175.9.6022

37. Sambri V, Marangoni A, Giacani L, Gennaro R, Murgia R, Cevenini R, et al. Comparative in vitro activity of five cathelicidin-derived synthetic peptides against Leptospira, Borrelia and Treponema pallidum. J Antimicrob Chemother. (2002) 50:895-902. doi: 10.1093/jac/dkf220

38. Lindow JC, Wunder EA Jr., Popper SJ, Min JN, Mannam P, Srivastava A, et al. Cathelicidin insufficiency in patients with fatal leptospirosis. PLoS Pathog. (2016) 12:e1005943. doi: 10.1371/journal.ppat.1005943

39. Song WS, Jeon YJ, Namgung B, Hong M, Yoon SI. A conserved TLR5 binding and activation hot spot on flagellin. Sci Rep. (2017) 7:40878. doi: 10.1038/ srep40878

40. Yoon SI, Kurnasov O, Natarajan V, Hong M, Gudkov AV, Osterman AL, et al. Structural basis of TLR5-flagellin recognition and signaling. Science. (2012) 335:859-64. doi: 10.1126/science.1215584

41. Forstneric V, vicak-Kocjan KI, Plaper T, Jerala R, Bencina M. The role of the C-terminal D0 domain of flagellin in activation of Toll like receptor 5. PLoS Pathog. (2017) 13:e1006574. doi: 10.1371/journal.ppat.1006574

42. Xu M, Xie Y, Tan M, Zheng K, Xiao Y, Jiang C, et al. The N-terminal D1 domain of Treponema pallidum flagellin binding to TLR5 is required but not sufficient in activation of TLR5. J Cell Mol Med. (2019) 23:7490-504. doi: $10.1111 / j \mathrm{cmm} .14617$

43. Kim JH, Namgung B, Jeon YJ, Song WS, Lee J, Kang SG, et al. Helicobacter pylori flagellin: TLR5 evasion and fusion-based conversion into a TLR5 agonist. Biochem Bioph Res Commun. (2018) 505:872-8. doi: 10.1016/j.bbrc. 2018.09.179

44. Jiang C, Xu M, Kuang X, Xiao J, Tan M, Xie Y, et al. Treponema pallidum flagellins stimulate MMP-9 and MMP-13 expression via TLR5 and MAPK/NFkappaB signaling pathways in human epidermal keratinocytes. Exp Cell Res. (2017) 361:46-55. doi: 10.1016/j.yexcr.2017.09.040

45. Goris MG, Wagenaar JF, Hartskeerl RA, van Gorp EC, Schuller S, Monahan $\mathrm{AM}$, et al. Potent innate immune response to pathogenic Leptospira in human whole blood. PLoS One. (2011) 6:e18279. doi: 10.1371/journal.pone.0018279

46. Forstneric V, vicak-Kocjan KI, Ljubetic A, Jerala R, Bencina M. Distinctive recognition of flagellin by human and mouse toll-like receptor 5. PLoS One. (2016) 11:e0158894. doi: 10.1371/journal.pone.01 58894

47. Ferrer MF, Scharrig E, Charo N, Ripodas AL, Drut R, Carrera Silva EA, et al. Macrophages and Galectin 3 control bacterial burden in acute and subacute murine leptospirosis that determines chronic kidney fibrosis. Front Cell Infect Microbiol. (2018) 8:384. doi: 10.3389/fcimb.2018.00384

48. Tahoun A, Jensen K, Corripio-Miyar Y, McAteer S, Smith DGE, McNeilly TN, et al. Host species adaptation of TLR5 signalling and flagellin recognition. Sci Rep. (2017) 7:17677. doi: 10.1038/s41598-017-17935-5 
49. Gomes-Solecki M, Santecchia I, Werts C. Animal models of leptospirosis: of mice and hamsters. Front Immunol. (2017) 8:58. doi: 10.3389/fimmu.2017. 00058

50. vicak-Kocjan KI, Forstneric V, Panter G, Jerala R, Bencina M. Extension and refinement of the recognition motif for Toll-like receptor 5 activation by flagellin. JLeukoc Biol. (2018) 104:767-76. doi: 10.1002/JLB.3VMA0118-035R

51. vicak-Kocjan KI, Panter G, Bencina M, Jerala R. Determination of the physiological 2:2 TLR5:flagellin activation stoichiometry revealed by the activity of a fusion receptor. Biochem Biophys Res Commun. (2013) 435:40-5. doi: 10.1016/j.bbrc.2013.04.030

52. Ruby J, Martin M, Passineau MJ, Godovikova V, Fenno JC, Wu H. Activation of the innate immune system by Treponema denticola periplasmic flagella through toll-like receptor 2. Infect Immun. (2018) 86:e0573-17. doi: 10.1128/ IAI.00251-18

53. Wang FB, virkaite-Krupovic VC, Kreutzberger MAB, Su ZL, de Oliveira GAP, Osinski T, et al. An extensively glycosylated archaeal pilus survives extreme conditions. Nat Microbiol. (2019) 4:1401-10. doi: 10.1038/s41564-019-0458-x

54. Kurniyati K, Kelly JF, Vinogradov E, Robotham A, Tu YB, Wang J, et al. A novel glycan modifies the flagellar filament proteins of the oral bacterium Treponema denticola. Mol Microb. (2017) 103:67-85. doi: 10.1111/mmi.13544

55. Charon NW, Cockburn A, Li CH, Liu J, Miller KA, Miller MR, et al. The unique paradigm of spirochete motility and chemotaxis. Annu Rev Microbiol. (2012) 66:349-70. doi: 10.1146/annurev-micro-092611-150145

56. Li C, Wolgemuth CW, Marko M, Morgan DG, Charon NW. Genetic analysis of spirochete flagellin proteins and their involvement in motility, filament assembly, and flagellar morphology. J Bacteriol. (2008) 190:5607-15. doi: 10.1128/JB.00319-08
57. Chou LF, Chen TW, Yang HY, Chang MY, Hsu SH, Tsai CY, et al. Murine renal transcriptome profiles upon leptospiral infection: implications for chronic kidney diseases. J Infect Dis. (2018) 218:1411-23. doi: 10.1093/infdis/ jiy339

58. Li C, Sal M, Marko M, Charon NW. Differential regulation of the multiple flagellins in spirochetes. J Bacteriol. (2010) 192:2596-603. doi: 10.1128/JB. 01502-09

59. Kim MI, Lee C, Park J, Jeon BY, Hong M. Crystal structure of Bacillus cereus flagellin and structure-guided fusion-protein designs. Sci Rep. (2018) 8:5814. doi: 10.1038/s41598-018-24254-w

60. Carrillo-Casas EM, Hernandez-Castro R, Suarez-Guemes F, de la PenaMoctezuma A. Selection of the internal control gene for real-time quantitative rt-PCR assays in temperature treated Leptospira. Curr Microbiol. (2008) 56:539-46. doi: 10.1007/s00284-008-9096-x

Conflict of Interest: The authors declare that the research was conducted in the absence of any commercial or financial relationships that could be construed as a potential conflict of interest.

Copyright (c) 2020 Holzapfel, Bonhomme, Cagliero, Vernel-Pauillac, Fanton d'Andon, Bortolussi, Fiette, Goarant, Wunder, Picardeau, Ko, Werling, Matsui, Boneca and Werts. This is an open-access article distributed under the terms of the Creative Commons Attribution License (CC BY). The use, distribution or reproduction in other forums is permitted, provided the original author(s) and the copyright owner(s) are credited and that the original publication in this journal is cited, in accordance with accepted academic practice. No use, distribution or reproduction is permitted which does not comply with these terms. 